\title{
Comprehensive phenotyping and transcriptome profiling to study nanotoxicity in C. elegans
}

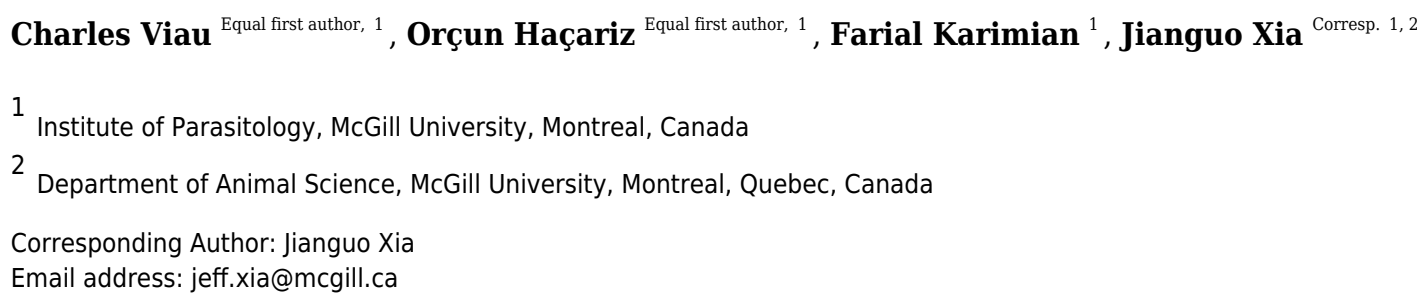

Engineered nanoparticles are used at an increasing rate in both industry and medicine without fully understanding their impact on health and environment. The nematode Caenorhabditis elegans is a suitable model to study the toxic effects of nanoparticles as it is amenable to comprehensive phenotyping, such as locomotion, growth, neurotoxicity and reproduction. In this study, we systematically evaluated the effects of silver ( $\mathrm{Ag})$ and five metal oxide nanoparticles: $\mathrm{SiO}_{2}, \mathrm{CeO}_{2}, \mathrm{CuO}, \mathrm{Al}_{2} \mathrm{O}_{3}$ and $\mathrm{TiO}_{2}$. The results showed that $\mathrm{Ag}$ and $\mathrm{SiO}_{2}$ exposures had the most toxic effects on locomotion velocity, growth and reproduction, whereas $\mathrm{CeO}_{2}, \mathrm{Al}_{2} \mathrm{O}_{3}$ and $\mathrm{CuO}$ exposures were mostly neurotoxic. We further performed RNAseq to compare the gene expression profiles underlying $\mathrm{Ag}$ and $\mathrm{SiO}_{2}$ toxicities. Gene set enrichment analyses revealed that exposures to $\mathrm{Ag}$ and $\mathrm{SiO}_{2}$ consistently downregulated several biological processes (regulations in locomotion, reproductive process and cell growth) and pathways (neuroactive ligand-receptor interaction, wnt and MAPK signaling, etc.), with opposite effects on genes involved in innate immunity. Our results contribute to mechanistic insights into toxicity of $\mathrm{Ag}$ and $\mathrm{SiO}_{2}$ nanoparticles and demonstrated that $C$. elegans as a valuable model for nanotoxicity assessment. 
1 Comprehensive phenotyping and transcriptome profiling to study nanotoxicity in $C$. elegans

2

3 Charles Viau $^{1^{\circ}}$, Orçun Haçariz ${ }^{1}$, Farial Karimian ${ }^{1}$ and Jianguo Xia ${ }^{1,2^{*}}$

$4{ }^{\circ}$ Authors both contributed equally

$5{ }^{1}$ Institute of Parasitology, and ${ }^{2}$ Department of Animal Science, McGill University, Montreal,

6 Quebec, Canada

7

8 *To whom correspondence should be addressed:

9 Tel: $1-514-398-8668$

10 Email: jeff.xia@mcgill.ca

11

12

13

14

15 


\section{Abstract}

17 Engineered nanoparticles are used at an increasing rate in both industry and medicine without fully

18 understanding their impact on health and environment. The nematode Caenorhabditis elegans is a

19 suitable model to study the toxic effects of nanoparticles as it is amenable to comprehensive

20 phenotyping, such as locomotion, growth, neurotoxicity and reproduction. In this study, we

21 systematically evaluated the effects of silver $(\mathrm{Ag})$ and five metal oxide nanoparticles: $\mathrm{SiO}_{2}, \mathrm{CeO}_{2}$,

$22 \mathrm{CuO}, \mathrm{Al}_{2} \mathrm{O}_{3}$ and $\mathrm{TiO}_{2}$. The results showed that $\mathrm{Ag}$ and $\mathrm{SiO}_{2}$ exposures had the most toxic effects

23 on locomotion velocity, growth and reproduction, whereas $\mathrm{CeO}_{2}, \mathrm{Al}_{2} \mathrm{O}_{3}$ and $\mathrm{CuO}$ exposures were

24 mostly neurotoxic. We further performed RNAseq to compare the gene expression profiles

25 underlying $\mathrm{Ag}$ and $\mathrm{SiO}_{2}$ toxicities. Gene set enrichment analyses revealed that exposures to $\mathrm{Ag}$

26 and $\mathrm{SiO}_{2}$ consistently downregulated several biological processes (regulations in locomotion,

27 reproductive process and cell growth) and pathways (neuroactive ligand-receptor interaction, wnt

28 and MAPK signaling, etc.), with opposite effects on genes involved in innate immunity. Our

29 results contribute to mechanistic insights into toxicity of $\mathrm{Ag}$ and $\mathrm{SiO}_{2}$ nanoparticles and

30 demonstrated that $C$. elegans as a valuable model for nanotoxicity assessment. 

42 2010).

\section{Introduction}

The use of engineered nanoparticles has increased enormously over the last decade, and the nanotechnology industry has grown from a 10-billion-dollar enterprise in 2012 to being valued over one trillion dollars in 2015 (Gao et al., 2011). However, the potential impacts of these nanoparticles on environment and animals have not been fully characterized and further research is warranted. Nanoparticles are defined as particulate matter ranging from 1 to $100 \mathrm{~nm}$ in size with properties not exhibited by their larger bulk counterparts (Khanna et al., 2015; Capco \& Chen, 2014; Maynard, 2011; Djurišić et al., 2015). The reactivity of nanoparticles depends on their size, charge, dose as well as the chemical composition of their coating (Medina et al., 2007). For instance, the surface area of smaller nanoparticles is larger compared to their larger counterparts, meaning they are more reactive and hence have a larger propensity of being toxic (Oberdörster,

Caenorhabditis elegans is a free-living soil nematode reaching approximately one millimeter in length in adult stage and has a relatively simple life cycle that can be grown on solid (i.e. nematode growth medium, NGM) or liquid media (i.e. S-medium) (Brenner, 1974; Lewis \& Fleming, 1995). The small size and relatively cheap maintenance cycle of $C$. elegans make the nematode very amenable for various phenotype screening. C. elegans has been well-established as an in vivo model for testing the effects of heavy metals and novel anthelminthics (Kaletta \& Hengartner, 2006; Ruiz-Lancheros et al., 2011). In terms of conservation of genes and biological pathways with humans, C. elegans shares 60 to $80 \%$ gene homology and possesses 12 of the 17 known signal transduction pathways (Kaletta \& Hengartner, 2006; National Research Council, 2000).

52 To validate our use of $C$. elegans as a model for nanotoxicity, as this bacterivore worm constantly interacts with microbes in nature, which are ingested through the pharynx, the main potential route 
54 of exposure to nanoparticles is consequently oral (Pluskota et al., 2009). Similarly, human

55

56

57

58 exposure to nanoparticles is also mostly through an oral route of entry, as nanoparticles are added to food in significant amount; the most prevalent ones being $\mathrm{Ag}, \mathrm{SiO}_{2}, \mathrm{TiO}_{2}$ and $\mathrm{ZnO}$ (Fröhlich \& Roblegg, 2016). For example, it is estimated a $70 \mathrm{~kg}$ individual ingests $126 \mathrm{mg}$ of Ag nanoparticles per day in Europe (Dekkers et al. 2011). The nematode worm C. elegans, as a model organism, is thus valid for studying nanotoxicity in higher eukaryotic organisms such as humans. Additionally, a second route of exposure is through the worm's vulval slit, where nanoparticles interfere with vulval cells and spermatecae (A. Scharf, K. H. Gührs \& A. von Mikecz, 2016). However, two routes of exposure to nanoparticles that cannot be studied in C. elegans are respiratory and dermal absorption, which are prevalent routes of exposure to nanoparticles for humans (Fröhlich \& Roblegg, 2016).

The fast phenotyping of $C$. elegans can be coupled with transcriptome profiling (i.e. gene expression microarray or RNAseq) to study underlying molecular mechanisms. For instance, using gene expression microarray, Rocheleau et al. found that $C$. elegans exposed to nano- $\mathrm{TiO}_{2}$ showed increased expression of the glutathione S-transferase gene gst-3 and the cytochrome P450 gene cyp33-11; while the oxidative stress response, as measured by the stress resistance regulator $s c l-1$, showed increased expression after exposure to both nano- and bulk-sized $\mathrm{TiO}_{2}$ (Rocheleau et al. 2015). In addition, the expression of $p o d-2$, a reproduction-related gene, was decreased in a concentration-dependent manner with nano- $\mathrm{TiO}_{2}$ exposure (Rocheleau et al. 2015). Based on the same technology, Starnes et al. identified that five lysosomal pathway related genes, including genes encoding the cysteine proteases $c p r-1$ and $c p r-2$, were changed significantly after exposure to silver (Ag) nanoparticles (Starnes et al. 2016). To the best of our knowledge, no transcriptome profiling has been reported to investigate $\mathrm{SiO}_{2}$ nanoparticles in C. elegans. The main objective of 
77 the current study is to develop and to evaluate a $C$. elegans-based animal model to study

78

nanotoxicity by integrating comprehensive phenotyping and transcriptome profiling. We selected $\mathrm{Ag}$ and five metal oxide nanoparticles $\left(\mathrm{SiO}_{2}, \mathrm{TiO}_{2}, \mathrm{CuO}, \mathrm{Al}_{2} \mathrm{O}_{3}\right.$ and $\left.\mathrm{CeO}_{2}\right)$, and measured four endpoints (locomotion velocity, growth, reproduction and neurotoxicity) in C. elegans after exposure to these nanoparticles. Worms that exhibited the most significant effects were subjected to RNAseq to identify the affected biological processes and pathways. Hence, we offer a novel perspective to study nanoparticle toxicity using the soil nematode C. elegans.

\section{Materials and Methods}

Caenorhabditis elegans culture. The C. elegans N2 strain was obtained from the Caenorhabditis Genetics Center (CGC) at the University of Minnesota. Escherichia coli OP50 was also obtained from the CGC and was grown for 18 hours at $37^{\circ} \mathrm{C}$ in Luria-Bertani (LB) broth (Bertani, 1951). The N2 strain was maintained at $21^{\circ} \mathrm{C}$ in an incubator on Nematode Growth Media (NGM) plates and C. elegans were synchronized using $5.0 \mathrm{ml}$ of alkaline bleach to kill the adult hermaphrodites and release their eggs (Stiernagle, 2006). Eggs were then washed three times with M9 buffer and left overnight on a rocking platform at room temperature to hatch into L1 larvae (Stiernagle, 2006).

Preparation of nanoparticles. $\mathrm{Ag}, \mathrm{SiO}_{2}, \mathrm{CuO}, \mathrm{Al}_{2} \mathrm{O}_{3}$, and $\mathrm{CeO}_{2}$ nanoparticles were purchased from Sigma-Aldrich (St. Louis, USA). $\mathrm{TiO}_{2}$ nanoparticles were obtained from the Joint Research Center of (JRC) the European Commission. All nanoparticles were less than $100 \mathrm{~nm}$ in size as described by the manufacturer and commission. Product details are shown in Table 1. Nanoparticles were dissolved at stock concentration of $1,000 \mu \mathrm{g} / \mathrm{ml}$ in $\mathrm{ddH}_{2} \mathrm{O}$ and sonicated using an Ultrasonic Processor VCX (GEX) 750 at an amplitude of 40\% for a 3-minute pulse, followed 
99

100

101

102

103

104

105

106

107

108

109

110

111

112

113

114

115

116

117

118

119

120

by 1 minute on ice. This step was repeated five times to ensure complete disaggregation of the nanoparticles. Nanoparticle solutions were then diluted to working concentrations of $200 \mu \mathrm{g} / \mathrm{ml}$ in S-medium (Jung et al., 2015).

Locomotion velocity and growth (body length) assays. 200 L1 stage C. elegans N2, obtained after synchronization with alkaline bleach, were grown in S-medium in 6-well plates containing 0 (control), 10 or $50 \mu \mathrm{g} / \mathrm{ml}$ of each nanoparticle, supplemented with E. coli OP50 at a final optical density at $595 \mathrm{~nm}\left(\mathrm{OD}_{595}\right)$ of 1 , for 72 hours at $21^{\circ} \mathrm{C}$ until they reached the day 1 adult stage. For the locomotion velocity endpoint assay, worms were then washed once in 1X M9 buffer and placed on unseeded NGM plates and allowed to explore their surroundings for 10 minutes. Worms $(\mathrm{n}=$ 14 to 111 per condition) were then recorded using a Nikon camera (SMZ1270) linked to a computer. The average locomotion velocity of each worm was calculated for 30 seconds at an interval of 0.500 milliseconds using the software (NIS-Elements, version 4.60) accompanying the camera. The average locomotion velocity was calculated by averaging the locomotion velocity (in $\mu \mathrm{m} / \mathrm{s}$ ) over the 30 seconds of recording. For the growth (body length) endpoint assay, worms were grown in the same manner as in the locomotion velocity endpoint assay, washed once in 1X M9 buffer and killed with $10 \mathrm{mM}$ sodium azide. Dead worms were transferred to an unseeded NGM plate to take pictures. The body length of worms $(n=20$ to 43 per condition), measured in $\mu \mathrm{m}$, was calculated using the camera's software (NIS-Elements, version 4.60).

Reproduction (brood size) assay. 200 L1 C. elegans N2, obtained by synchronization, were grown for 48 hours at $21^{\circ} \mathrm{C}$ to the L4-young adult stage on E. coli OP50-seeded NGM plates. Five L4-young adult hermaphrodites were transferred to an individual well in quadruplicate of a 12well plate containing S-medium supplemented with either 0 (control), 10 or $50 \mu \mathrm{g} / \mathrm{ml}$ of each 
121 nanoparticle and E. coli OP50. The L4-young-adult hermaphrodites were then allowed to grow

122 and lay eggs for 96 hours, and resulting progeny were counted by dilution.

123 Neurotoxicity (number of head thrashes) assay. 200 L1 C. elegans N2 were grown to the adult 124 day 1 stage $\left(72\right.$ hours at $\left.21^{\circ} \mathrm{C}\right)$ in individual wells of a 6 -well plate containing S-medium containing 125 either 0 (control), 10 or $50 \mu \mathrm{g} / \mathrm{ml}$ of each nanoparticle and E. coli OP50. A total of $1.0 \mathrm{ml}$ of the 126 well contents were centrifuged at 1,000 rpm for 2 minutes, the supernatant was decanted, leaving 127 the worm pellet undisturbed. Worms were then washed in 1X M9 buffer and centrifuged at 1,000 $128 \mathrm{rpm}$ for 2 minutes. Worms were then transferred to an unseeded NGM plate containing $60 \mu \mathrm{l}$ of $129 \mathrm{~K}$-medium $\left(2.36 \mathrm{~g}\right.$ of $\mathrm{KCl}$ and $3.0 \mathrm{~g} \mathrm{NaCl}$ per liter of media dissolved in $\left.\mathrm{ddH}_{2} \mathrm{O}\right)$. Individual adult 130 day 1 stage $C$. elegans were transferred into the drop of K-medium. Worms were allowed to swim 131 freely for 1 minute. Afterwards, the number of head thrashes of each individual worm $(\mathrm{n}=8$ to 55 132 per condition) were counted for 1 minute as described by Tsalik \& Hobert (2003).

Total RNA extraction of worms exposed to $\mathbf{A g}$ and $\mathrm{SiO}_{2}$ nanoparticles. $400 \mathrm{~L} 1$ C. elegans $\mathrm{N} 2$

134

were grown in individual wells of a 12-well plate containing either $0,10 \mu \mathrm{g} / \mathrm{ml} \mathrm{Ag}$ nanoparticles or $10 \mu \mathrm{g} / \mathrm{ml} \mathrm{SiO}_{2}$ nanoparticles and supplemented with $E$. coli OP50, until the worms reached the adult day 1 stage $\left(72\right.$ hours at $\left.21^{\circ} \mathrm{C}\right)$. Each condition was repeated six times. The contents of the wells were centrifuged at 1,000 rpm for 2 minutes, the supernatant was decanted and the worm pellet was washed twice with 1X M9 buffer. $200 \mu 1$ of Trizol (Ambion, USA) was then added to the worm pellet. The worm pellet then was flash-frozen in liquid nitrogen, followed by a quick thaw. These two steps were repeated once. RNA from the resulting worm pellet-Trizol solution was extracted using the Direct-zol RNA miniprep kit (Zymo Research, USA) according to the manufacturer's instructions. Quantity and purity of total RNA were checked using a spectrophotometer (ND-1000, NanoDrop). The RNA samples were then sent to the McGill 
144 University and Génome Québec Innovation Centre (http://gqinnovationcenter.com) for quality

145 analysis with Bioanalyser and for single-end read (100 base) RNA sequencing under HiSeq 2500

146 (Illumina).

147 Data analysis for RNAseq: Raw data for each sample was received in fastq file format from the

148 McGill University and Génome Québec Innovation Centre. Read quality was checked with

149 FASTQC (version 0.11.3) and adapter related sequences were removed using Trim Galore

150 (version 0.4.5) (https://www.bioinformatics.babraham.ac.uk/projects/). The genome sequence of

151 C. elegans and GTF file (Caenorhabditis_elegans.WBcel235.91.gtf) were downloaded from

152 ENSEMBL (https://www.ensembl.org/). Reads were aligned to the C. elegans genome with

153 HISAT2 (version 2.1.0) (Kim, Langmead \& Salzberg, 2015) and sorted alignment files were

154 generated by SAMtools (version 1.7) (Li et al., 2009). Raw read counts were extracted using

155 HTSeq (version 0.9.1) with the intersection-strict mode (Anders, Pyl \& Huber, 2015). Entrez IDs

156 were extracted from a Bioconductor package (org.Ce.eg.db) (Carlson, 2018) and assigned to the

157 wormbase gene sequences using R. Sample distribution by principal component analysis was

158 visualised using NetworkAnalyst 3.0 (Zhou et al., 2019). Differential gene expression analysis

159 between the nanoparticle treatments and control was carried out using edgeR where data were

160 normalised by trimmed mean of M-values (TMM) and tag-wise dispersion parameters were

161 estimated using the empirical Bayes method (Robinson, McCarthy \& Smyth, 2010). For gene set

162 enrichment analysis, genes were ranked by the expression ratio (combination of log 2 fold change

163 and FDR) and normalized enrichment score (NES) was determined using GSEAPreranked in Gene

164 Set Enrichment Analysis (GSEA; version 3.0) (Subramanian et al., 2005). The value for the

165 parameter of min size: exclude smaller sets was set to 0 , the value for permutations was set to 1000

166 and the enrichment statistic was set to classic. For use with GSEAPreranked, GO derived MSigDB 
167 format gene sets for C. elegans was downloaded from GO2MSIG (Powell, 2014) and KEGG

168 database of C. elegans was extracted from a current Bioconductor package (version 3.7) (Luo et

169 al., 2009) and converted to *gmt file. Pathway interaction was investigated using ClueGO (Bindea

170 et al. 2009). Furthermore, gene enrichment in GO and newly determined terms were carried out

171 using GOATOOLS (Klopfenstein et al., 2018) and WormExp (Yang, Dierking, \& Schulenburg,

172 2016), respectively. Differentially expressed genes in the toxicity groups (compared to control)

173 were further searched to ascertain whether they were reported in metal toxicity based on previous

174 studies (Caito et al., 2012; Cui et al., 2007; Roh, Lee \& Choi, 2006; Kumar et al., 2015; Anbalagan

175 et al., 2012).

176 Statistical analysis: Statistical analysis was performed using GraphPad Prism (version 8.0.0). The

177 statistical difference between the groups in the toxicity assays was evaluated with One-way 178 ANOVA followed by Dunnett's multiple comparison test and P value less than 0.05 was accepted 179 as statistically significant.

\section{Results}

The pooled average locomotion velocity for C. elegans grown under control conditions was 150.1 $\mu \mathrm{m} / \mathrm{s}$ across all treatments, indicating that worms are active after growth in S-medium for 72 hours at $21^{\circ} \mathrm{C}$. In comparison, the average locomotion velocity of worms decreased to $91.5 \mu \mathrm{m} / \mathrm{s}$ in the presence of $10 \mu \mathrm{g} / \mathrm{ml} \mathrm{Ag} \mathrm{nanoparticles} \mathrm{and} \mathrm{further} \mathrm{reduced} \mathrm{to} 44.2 \mu \mathrm{m} / \mathrm{s}$ in the presence of 50 $\mu \mathrm{g} / \mathrm{ml} \mathrm{Ag}$ nanoparticles, which was statistically significant for each concentration $(\mathrm{P}=0.0001$ and $\mathrm{P}<0.0001$, respectively) (Fig. 1A). Additionally, the difference in the reduction levels by the concentrations $(>50 \%)$ indicated a dose-dependent decrease in average locomotion velocity in 
189 response to increasing Ag nanoparticle concentration. The second nanoparticle to influence the 190 worms' average locomotion velocity was $\mathrm{SiO}_{2}$, which caused significant decreases at 10 or 50 $191 \mu \mathrm{g} / \mathrm{ml}$ doses in comparison with control ( $\mathrm{P}<0.0001$ for both concentrations). Surprisingly, it 192 appeared that $\mathrm{TiO}_{2}$ nanoparticles increased $C$. elegans average locomotion velocity at $10 \mu \mathrm{g} / \mathrm{ml}(\mathrm{P}$ $193=0.0257$, although this could be a statistical artifact due to sampling effect based on the data 194 distribution (Fig. 1C). $\mathrm{Al}_{2} \mathrm{O}_{3^{-}}, \mathrm{TiO}_{2^{-}}$and $\mathrm{CuO}$-treated $C$. elegans showed decreases in average 195 locomotion velocity when tested at $50 \mu \mathrm{g} / \mathrm{ml}\left(\mathrm{P}=0.0196\right.$, for $\mathrm{Al}_{2} \mathrm{O}_{3}$ and $\mathrm{P}<0.005$ for both $\mathrm{TiO}_{2}$ and $\mathrm{CuO}$ ), displaying locomotion velocities of 104.4, 114.8 and $112.2 \mu \mathrm{m} / \mathrm{s}$, respectively (Figs. $1 \mathrm{C}, \mathrm{D}$ and $\mathrm{E}) . \mathrm{CeO}_{2}$ nanoparticles had no effect at any of the concentrations tested $(\mathrm{P}>0.05$, for both concentrations).

For the growth inhibition (body length) assay, Ag nanoparticles had the greatest effect. The pooled average body length of worms grown in the control S-medium after a three-day incubation at $21^{\circ} \mathrm{C}$ was $1199.6 \mu \mathrm{m}$, indicating that the worms grew efficiently in this medium. As with the locomotion velocity endpoint assay, a concentration-dependent decrease in body length was observed when worms were exposed to different concentrations of Ag nanoparticles, with average body lengths of $1017.8 \mu \mathrm{m}$ under $10 \mu \mathrm{g} / \mathrm{ml}$ and $859.3 \mu \mathrm{m}$ under $50 \mu \mathrm{g} / \mathrm{ml}$, respectively $(\mathrm{P}<0.0001$ for both concentrations) (Fig. 2A). Exposure to $\mathrm{SiO}_{2}$ nanoparticles induced significant decrease at $10 \mu \mathrm{g} / \mathrm{ml}$ 206 $(\mathrm{P}<0.0001)$ (Fig. 2B), but no further significant decrease was observed at $50 \mu \mathrm{g} / \mathrm{ml}$. Exposure to $\mathrm{CuO}$ nanoparticles also resulted in a concentration-dependent decrease in body length, leading to 208 an average body length of 1055.3 and $923.1 \mu \mathrm{m}$, respectively $(\mathrm{P}<0.0001$ for both concentrations) (Fig. 2F). For $\mathrm{CeO}_{2}$ and $\mathrm{Al}_{2} \mathrm{O}_{3}$ nanoparticles, significant decreases in body length were observed 210 at $10 \mu \mathrm{g} / \mathrm{ml}$ compared to control worms $(\mathrm{P}<0.0001$, Figs. $2 \mathrm{D}$ and $\mathrm{E})$. For $\mathrm{TiO}_{2}$ nanoparticles, a 211 significant difference was observed only at $50 \mu \mathrm{g} / \mathrm{ml}$, in which the exposed worms showed an 
212 average body length of $1130.8 \mu \mathrm{m}(\mathrm{P}=0.001)$ (Fig. 2C). In summary, these results show Ag and

$213 \mathrm{SiO}_{2}$ nanoparticles have similar toxicity on $C$. elegans, although the effect appears to be

214 concentration-dependent for $\mathrm{Ag}$ nanoparticles whereas there is likely a threshold effect for $\mathrm{SiO}_{2}$

215 nanoparticles.

216 To measure the effects of the various nanoparticles on C. elegans reproduction, we incubated five

217 L4-young adults in S-medium supplemented with E. coli OP50 and the respective nanoparticles

218 for four days (96 hours) at $21^{\circ} \mathrm{C}$. It was expected that each worm would lay approximately 300

219 eggs in that time span, so that the total number of progeny per 5 worms would be near 1,500 under

220 control conditions (Sulston \& Hodgkin, 1988; Sonowal et al., 2017). The average control value of

221 progeny produced by 5 worms under our experimental conditions was 1,288 after 96 hours. We

222 found that most nanoparticles reduced the number of progeny produced by C. elegans. At 10

$223 \mu \mathrm{g} / \mathrm{ml}$, Ag nanoparticles decreased the brood size of $C$. elegans to around 37\%, which was

224 statistically significant $(\mathrm{P}<0.0001)$ (Fig.3A). The effect was even more pronounced at $50 \mu \mathrm{g} / \mathrm{ml}$,

225 as Ag nanoparticles decreased the number of progeny to $33 \%$ of the control value, suggesting that

226 these nanoparticles do indeed decrease $C$. elegans brood size $(\mathrm{P}<0.0001)$ (Fig. 3A). On the other

227 hand, $\mathrm{SiO}_{2}$ nanoparticles decreased brood size substantially at both $10 \mu \mathrm{g} / \mathrm{ml}$ and $50 \mu \mathrm{g} / \mathrm{ml}(\mathrm{P}<$

228 0.0001) (Fig. 3B), indicating that $\mathrm{SiO}_{2}$ nanoparticles are potent inhibitors of C. elegans

229 reproduction in concentrations ranging in $\mu \mathrm{g} / \mathrm{ml}$. In contrast, $\mathrm{TiO}_{2}$ nanoparticles, known to inhibit

230 C. elegans reproduction, reduced brood size to about $80 \%$ of the control value in our testing

231 concentration range (Fig. 3C). $\mathrm{CeO}_{2}$ nanoparticles inhibited C. elegans reproduction as well. The

232 brood size decreased to $55 \%$ of the control-treated value at a concentration of $10 \mu \mathrm{g} / \mathrm{ml}(\mathrm{P}=$

2330.0002 ) (Fig. 3D). Interestingly, at $50 \mu \mathrm{g} / \mathrm{ml}$, the decrease was not as pronounced, equating to $89 \%$

234 of the control-treated value $(\mathrm{P}>0.05)$ (Fig. 3D). This observation may be due to the aggregation 
235 of $\mathrm{CeO}_{2}$ at higher concentrations. $\mathrm{Al}_{2} \mathrm{O}_{3}$ nanoparticles did not show statistically significant effects

236 on C. elegans under our conditions $(\mathrm{P}>0.05)($ Fig. 3E), whereas $\mathrm{CuO}$ nanoparticles decreased the

237 brood size value to $83 \%$ and $71 \%$ of the control value, at $10 \mu \mathrm{g} / \mathrm{ml}$ and $50 \mu \mathrm{g} / \mathrm{ml}$, respectively (Fig. $2383 \mathrm{~F})$.

239 Both $\mathrm{Ag}$ and $\mathrm{SiO}_{2}$ nanoparticles showed no significant impact of the number of head thrashes 240 based on a population of worms in 60 seconds at $10 \mu \mathrm{g} / \mathrm{ml}$ versus control worms (Fig.4A and 4B).

$241 \mathrm{SiO}_{2}$ nanoparticles showed a slight effect on the neurotoxicity assay at $50 \mu \mathrm{g} / \mathrm{ml}(\mathrm{P}=0.0033)$,

242 whereas Ag nanoparticles had no such effect on neurotoxicity. Similar results were observed for

$243 \mathrm{TiO}_{2}$ and nanoparticles at both concentrations tested (Fig.4C). In contrast, $\mathrm{CeO}_{2}, \mathrm{Al}_{2} \mathrm{O}_{3}$ and $\mathrm{CuO}$

244 nanoparticles showed significant effects on neurotoxicity at $10 \mu \mathrm{g} / \mathrm{ml}$ under our conditions, as

245 determined by a significant decrease in the number of head thrashes, and this trend was conserved

246 at $50 \mu \mathrm{g} / \mathrm{ml}\left(\mathrm{P}<0.0001\right.$ for both $\mathrm{CeO}_{2}$ concentrations, $\mathrm{P}=0.0087$ and $\mathrm{P}<0.0001$ for $\mathrm{Al}_{2} \mathrm{O}_{3}$ at 10

$247 \mu \mathrm{g} / \mathrm{ml}$ and $50 \mu \mathrm{g} / \mathrm{ml}$, respectively and $\mathrm{P}=0.0002$ for $\mathrm{CuO}$ at $10 \mu \mathrm{g} / \mathrm{ml}$ ), although the effect on

248 neurotoxicity of $\mathrm{CuO}$ nanoparticles at $50 \mu \mathrm{g} / \mathrm{ml}$ was not significant (P > 0.05) (Figs.4D-F).

249 Based on the phenotyping results, we further performed RNAseq analysis on C. elegans exposed 250 to $\mathrm{Ag}$ and $\mathrm{SiO}_{2}(10 \mu \mathrm{g} / \mathrm{ml})$ as these two nanoparticles demonstrated the most outstanding effect on 251 majority of the parameters (locomotion velocity, growth and reproduction). For each sample (5 252 replicates for the $\mathrm{Ag}, \mathrm{SiO} 2$ and control groups), around 20 million reads were obtained. 253 Approximately $97 \%$ of reads were mapped to the worm's genome and a total of 18,861 gene 254 sequences were identified, using a minimal total read count of 3 across samples. Sample 255 distribution by principal component analysis (PCA) is shown in Supplementary figure 1. 256 Differentially expressed genes (DEGs) based on edgeR between control and the toxicity groups 
257 (2,648 DEGs in the Ag group and 1,087 DEGs in the SiO2 group) are shown in Supplementary

258 data $1($ FDR $<0.05)$.

259 Gene set enrichment analysis (GSEA) based on Gene Ontology biological processes (BPs) showed 260 various statistically enriched positively or negatively based on the fold changes and running 261 enrichment scores (Supplementary data 2). The top 20 and phenotype reflecting enriched BPs are

262 shown in Table 2 (FDR $<0.05)$. These BPs were related to various physiological events such as 263 cellular and metabolic responses. Apoptotic process showed gene enrichment with positive NES 264 in both $\mathrm{Ag}$ and $\mathrm{SiO} 2$ groups under significant levels (FDR < 0.0001). Phenotype reflecting BPs 265 including regulation of locomotion, reproductive process and cell growth were enriched with 266 negative NES significantly $($ FDR $<0.0001$ for regulation of locomotion, FDR $=0.001$ for 267 regulation of reproductive process, FDR $=0.002$ for regulation of cell growth in the Ag group; $268 \mathrm{FDR}<0.0001$ for regulation of locomotion, $\mathrm{FDR}=0.008$ for regulation of reproductive process, $269 \mathrm{FDR}=0.042$ for regulation of cell growth in the $\mathrm{SiO} 2$ group) (Fig. 5). A number of genes were 270 commonly detected within the top five category in the phenotype reflecting enriched BPs for both $271 \mathrm{Ag}$ and $\mathrm{SiO} 2$ groups, including transcription factor (che-1) and MiRP K channel accessory subunit 272 (mps-1) in regulation of locomotion, caveolin (cav-1) in regulation of reproductive process, and 273 cyclic nucleotide-gated cation channel (tax-4) and protein let-756 (let-756) in regulation of cell 274 growth (Supplementary data 2).

275 The other significantly enriched BPs were associated with various physiological events and 276 immune defense of the organism. As both $\mathrm{Ag}$ and $\mathrm{SiO}_{2}$ nanoparticles were foreign substances for 277 the worm, we further examined the expression profiles of genes associated with innate immunity.

278 Compared to $\mathrm{Ag}$ and Control, $\mathrm{SiO}_{2}$ exposure led to significant downregulations of genes related 279 to the innate immune response $(\mathrm{FDR}<0.0001)$ (Fig. 6). 
280 The enriched BPs by GOATOOLS were mainly related to the physiological events, of which, some

281 were identical to those observed by the GSEA analysis (Supplementary data 2). However, the

282 number of the BPs detected by GOATOOLS was lower compared to those detected by GSEA,

283 which was likely related to the differences in gene inputs (DEGs with FDR $<0.05$ vs cut-off free

284 DEGs ranked by fold change) and/or the methodologies used. Nevertheless, the phenotype

285 reflecting BPs including the regulations of locomotion and reproductive process were also

286 enriched in the $\mathrm{Ag}$ group in the GOAtools analysis. However, this was not the case for the $\mathrm{SiO} 2$

287 group, which appeared to be related to lower number of DEGs in this group, compared to the Ag 288 group.

Analysis of the RNAseq data using WormExp showed gene enrichment in newly determined terms 290 (Supplementary data 2). Some of these terms were found associated with regulations of locomotion, reproduction and cell growth in both groups. The "glp-1 mutant" term was enriched in the $\mathrm{Ag}$ and $\mathrm{SiO} 2$ groups, which refers to the diminished reproductive capability of C. elegans (Gracida \& Eckmann, 2013). In regard to development terms, "pgl-1 mutant" and "P-granule RNAi” were enriched in the $\mathrm{Ag}$ and $\mathrm{SiO} 2$ groups, respectively, linking regulation of cell growth (Knutson et al. 2017). The "wdr-23 mutant" term was also present for both nanoparticle exposure groups. This is notable as wdr-23, through the action of skn-1, is involved in proper locomotion of C. elegans (Staab et al. 2013). Finally, the other terms, including regulation by heavy metals/NPs (such as Ag), were found for both groups, further validating the nanoparticle effect. Altogether, the WormExp gene enrichment terms, obtained from the RNAseq data, appear to be in agreement with the phenotypic assay results.

Pathway enrichment analysis against the KEGG database showed various significantly enriched pathways (Supplementary data 3). The top 20 enriched biological pathways are shown for both 
303 exposures in Table 3. Ribosome, proteasome, aminoacyl-tRNA biosynthesis and RNA transport 304 were significantly upregulated in both groups, indicating overall higher rate of protein turnover 305 upon exposure. In contrast, biological pathways reflecting phenotypes including neuroactive 306 ligand-receptor interaction [regulating locomotion (Kong et al. 2015)], wnt-signaling (regulating 307 reproduction and cell growth (Inoki et al. 2006; Hernandez Gifford, 2015) and MAPK signaling 308 (regulating reproduction and cell growth (Zhang \& Liu, 2002; Andrade et al., 2014) were 309 significantly down-regulated in both exposures (Fig. 7). Some genes were found commonly within 310 the top 5 enriched gene category in each enriched biological pathway for both $\mathrm{Ag}$ and $\mathrm{SiO}_{2}$ treatments (based on fold change and running enrichment score), which were tachykinin receptor

312 family (tkr-2), serotonin/octopamine receptor family (ser-1) in neuroactive ligand-receptor 313 interaction pathway, skp1 related (ubiquitin ligase complex component, skr-8, skr-10, skr-12) in 314 wnt signaling pathway, protein ver-1 (ver-1) and heat shock protein (hsp 70) in MAPK signaling 315 pathway (Supplementary data 3).

317 Discussion

318 As the use of nanoparticles has increased dramatically in recent years, there is a growing concern 319 regarding their potential impact to environment and human health. In this study, we have 320 systematically evaluated a C. elegans-based animal model for nanotoxicity assessment. Our results 321 have shown that $\mathrm{Ag}$ and $\mathrm{SiO}_{2}$ have the most potent toxic effect on locomotion velocity and growth, 322 as well as reproduction (brood size), but not on neurotoxicity. In this model, the transcriptome 323 profile is concordant with the phenotype characteristic for both exposures (Fig. 8). 
324 The top 20 GO BPs identified by the GSEA were related to various physiological events in the Ag 325 and $\mathrm{SiO} 2$ toxicities. The exposure to both nanoparticles downregulated multiple regulatory 326 biological processes, including regulation of locomotion, regulation of reproduction and regulation

327 of cell growth, which was consistent with the phenotype profiling of our study.

328 Dysfunction of the enriched genes including transcription factor che-1 (che-1) and MiRP K 329 channel accessory subunit (mps-1) (regulation of locomotion), caveolin (cav-1) (regulation of reproductive process), and cyclic nucleotide-gated cation channel (tax-4) and protein let-756 (let756) (regulation of cell growth), have been previously shown to hinder the worm's biological events (Uchida et al., 2003; Bianchi et al., 2003; Scheel et al., 1999; Komatsu et al., 1996; Roubin et al. 1999). Inactivation of che-1 (mediating chemotaxis through ASE neurons) and of mps-1 (a voltage-gated pore-forming potassium subunit) impairs neuronal activities such as chemotaxis and locomotion (Uchida et al., 2003; Bianchi et al., 2003). Caveolin-1 (cav-1), identified in the adult germ line and highly expressed in eggs, is required for Ras/MAP-kinase-dependent progression (Scheel et al., 1999). Inhibition of tax-4 and let-756 genes hinders chemosensation and results in larval arrest, respectively (Komatsu et al., 1996; Roubin et al. 1999).

Although biological processes reflecting phenotypes were similar between both toxicities in our study, $\mathrm{SiO}_{2}$ nanoparticles induced a remarkable downregulation pattern in innate immune response, compared to Ag and Control. In particular, several C-type lectins, which are known to

342 be important components in innate immunity (Mayer, Raulf \& Lepenies, 2017), appeared to be exclusively downregulated by $\mathrm{SiO}_{2}$ nanoparticles. The subject of nanoparticle exposure and the effects on immune system has been an active research area (Boraschi et al., 2017). Exposure to nanoparticles has been linked to changes in the immune response such as inflammation, hypersensitivity and immunosuppression and has been shown to induce such responses through 
347 antigen-presenting cells in humans, highlighting the interaction between nanoparticles and the 348 innate immune response (Alsaleh \& Brown, 2018). Biocoronas, formed by the interaction of the 349 nanoparticle surface with proteins and lipids, are highly reactive immunologically and have 350 recently gained the attention of regulatory agencies (Shannahan, 2017).

351 The top 20 significant KEGG pathways identified in both exposure studies are similar to the

352 findings based on GO BPs. In particular, the regulatory biological pathways linked to phenotypes, 353 including neuroactive ligand-receptor interaction [relates to locomotion (Inoki et al., 2016)], wnt 354 and MAPK signaling pathways [relates to reproduction and cell growth (Inoki et al., 2016; 355 Hernandez Gifford,2015; Zhang \& Liu, 2002; Andrade et al. 2014)], were found to be 356 downregulated in both experiments. The pathway interaction analysis by ClueGO showed that wnt 357 signaling pathway was interacting with tgf-beta pathway which was also enriched with 358 significantly negative NES in both toxicities. These signaling pathways are known to interact with 359 each other and control adult tissue homeostasis (Warner, Greene \& Pisano, 2005). The downregulation of genes involved in neuroactive ligand receptor interaction likely to be responsible for the changes in locomotion.

362 The genes within the top 5 enriched gene category in the indicated pathways, commonly observed 363 in both toxicities, were tachykinin receptor family (tkr-2), serotonin/octopamine receptor family 364 (ser-1) (neuroactive ligand-receptor interaction pathway), skp1 related (ubiquitin ligase complex 365 component, skr-8, skr-10, skr-12) (wnt signaling pathway), and protein ver-1 (ver-1) and heat 366 shock protein (hsp 70) (MAPK signaling pathway). The proteins encoded by tachykinin receptor 367 and ser-1 genes regulate locomotion via mediate neurotransmission and indirect modulation of 368 neuromuscular circuits, respectively (Pennefather, et al. 2004; Dernovici et al., 2007). The proteins encoded by skp1 related genes (such as skr-8 and skr-10) are known to be a core element of SCF 
370 ubiquitin-ligase complexes and involved in posterior body morphogenesis, embryonic and larval

371 development, and cell proliferation in C. elegans (Nayak et al., 2002). Putative vascular endothelial

372 growth factor receptors (VERs) of C. elegans and Hsp70 chaperones act in the PVF-1 signalling

373 pathway for ray 1 positioning (in the male worms) and mediate protein folding, influencing various

374 regulatory proteins, respectively (Dalpe et al, 2013; Mayer \& Bukau, 2005). Overall, these genes

375 may play significant roles on locomotion, reproduction and cell growth in response to nanotoxicity.

376 Apart from the many similarities observed between the two nanoparticle effects, $\mathrm{Ag}$ and $\mathrm{SiO}_{2}$ also

377 showed opposite effects on some of the top 20 enriched biological pathways. Spliceosome, mRNA

378 surveillance and endocytosis pathways were enriched with positive NES in Ag, but with negative

379 NES in SiO2, despite no obvious phenotypic differences were observed in our studies.

380 Comparison of the transcriptomics changes during $\mathrm{Ag}$ and $\mathrm{SiO}_{2}$ exposures with the findings in

381 previous studies on metal toxicities indicated that metallothionein-2 (mtl-2), a commonly observed

382 responsive gene to the metal toxicities (conserved in C. elegans and mammals) (Caito et al., 2012;

383 Cui et al., 2007; Roh, Lee \& Choi, 2006; Kumar et al., 2015; Anbalagan et al., 2012), was up-

384 regulated in these groups $(\mathrm{FDR}=0.002$ for $\mathrm{Ag}, \mathrm{FDR}=0.043$ for $\mathrm{SiO} 2)$, which further confirmed

385 the effectiveness of the model.

$386 \mathrm{Ag}$ and $\mathrm{SiO}_{2}$ nanoparticles have been shown to affect locomotion velocity in C. elegans $\mathrm{N} 2$, as

387 previously described (Jung et al., 2015). In addition, $\mathrm{Ag}$ and $\mathrm{SiO}_{2}$ have been shown to reduce brood 388 size, according to several studies (Kleiven et al., 2018; Wu et al., 2013; Pluskota et al., 2009). In contrast, we did not observe a significant decrease in brood size to exposure to 10 and $50 \mu \mathrm{g} / \mathrm{ml}$ of $390 \mathrm{TiO}_{2}$ nanoparticles, as observed by $\mathrm{Wu}$ et al. 2013, indicating differences in our conditions, as 391 these authors saw a slight decrease in progeny production when using these nanoparticles in the $392 \mu \mathrm{g} / \mathrm{l}$ concentration range. The effects of the other nanoparticles used in this study (i.e. $\mathrm{CuO}, \mathrm{Al}_{2} \mathrm{O}_{3}$, 
393 and $\mathrm{CeO}_{2}$ ) are relatively unknown based on the literature. In terms of neurotoxicity experiments,

394 as determined by the number of head thrashes per minute in our study, our results differ from 395 published results (Wu et al., 2013; Pluskota et al., 2009, Piechulek \& von Mikecz, 2018) which 396 show that $\mathrm{Ag}$ and $\mathrm{SiO}_{2}$ are neurotoxic at lower concentrations than the ones used in this study, 397 although $\mathrm{SiO}_{2}$ nanoparticles were found to have a modest effect at $50 \mu \mathrm{g} / \mathrm{ml}$ on neurotoxicity under 398 our conditions. Indeed, we noticed that many neuron system-related BPs or pathways were 399 enriched with negative NES in both $\mathrm{Ag}$ and $\mathrm{SiO} 2$ groups appear to have limited influence on head 400 thrashing in our analysis. Additionally, our study is different compared to the indicated studies, as 401 we only looked at the effect of nanoparticles incubated from the L1 stage to the adult day one 402 stage. We observed that $\mathrm{CeO}_{2}, \mathrm{Al}_{2} \mathrm{O}_{3}$ and $\mathrm{CuO}$ nanoparticles had significant neurotoxicity at 10 $403 \mu \mathrm{g} / \mathrm{ml}$, as determined by the decrease in number of head thrashes per minute, which is a novel 404 observation. The reported differences in this study may be because the $\mathrm{Ag}$ and $\mathrm{SiO}_{2}$ nanoparticles 405 used in our study were confirmed to have a spherical shape under the manufacturer's test 406 conditions (Table 1), whereas the others $\left(\mathrm{TiO}_{2}, \mathrm{CeO}_{2}, \mathrm{Al}_{2} \mathrm{O}_{3}\right.$ and $\left.\mathrm{CuO}\right)$ were unconfirmed to adopt 407 any shape at all. Further study is required to elucidate the answer to this question. It was shown 408 that co-feeding nanoparticles with E. coli OP50 in S-medium leads to the uptake of these 409 nanoparticles through the pharynx and absorption through the gut (Piechulek, Berwanger \& von 410 Mikecz, 2019). We speculate this to be true as well under our conditions. Silica $\left(\mathrm{SiO}_{2}\right)$ 411 nanoparticles were shown to inhibit the peptide transporter OPT-2/PEP-2, present on the apical 412 layer of the intestinal membrane in C. elegans (Piechulek, Berwanger \& von Mikecz, 2019). 413 Inhibition of the OPT-2/PEP-2 transporter leads to the accumulation of silica nanoparticles in gut 414 granules, indicating they are taken up within the organism. Fang-Yen et al. showed that particles 415 with a diameter range of $0.5 \mu \mathrm{m}$ to $3 \mu \mathrm{m}$ are taken up by the pharynx (Fang-Yen et al. 2009). We 
416 propose that this size range is circumvented when nanoparticles are co-fed with E. coli OP50 to

417 gain access to the gut for absorption.

418 The observed effects in the various experiments can be either nanoparticle-specific or compound-

419 /element-specific. Nanoparticles, ranging from 1 to $100 \mathrm{~nm}$ in size, are larger than their elemental

420 constituents, which are metal cations under our experimental conditions. We reason that the

421 observed effects in the various experiments and RNAseq analysis are due mainly to nanoparticles,

422 although nanoparticles, such as Ag, release positively-charged ions upon incubation in liquid

423 media and the proportion of released cations is small (Lekamge et al., 2018). In addition, metal

424 oxide nanoparticles tend to release ions into liquid medium depending on the cationic metal charge

425 (Simeone \& Acosta, 2015). For example, where $\mathrm{Z}$ is the oxidation number of the metal cation,

426 oxides of nanoparticle cations with $Z \leqslant 2$ dissolve more than $10 \%$, whereas this fraction is reduced

427 to less than $1 \%$ for nanoparticle oxides of cations with $Z>3$ (Simeone \& Acosta, 2015). According

428 to this relationship, we would expect that less than $1 \%$ of the metal oxide nanoparticles used in our

429 study to be dissolved, except for $\mathrm{CuO}$ nanoparticles which has a metal cation $\mathrm{Z}$ value of 2. As

430 evidence for our reasoning, the WormExp enrichment analysis identified the "Ag NPs" term

431 (Supplementary data 2).

432 To address whether the nanoparticles used in our study affected E. coli OP50 growth and thus C.

433 elegans feeding, we incubated E. coli OP50 with $50 \mu \mathrm{g} / \mathrm{ml}$ of each nanoparticle in S-medium

434 (Supplementary figure 2). Compared to E. coli OP50 alone, the treated E. coli OP50, with the

435 highest concentration of nanoparticles $(50 \mu \mathrm{g} / \mathrm{ml})$, demonstrated only slight growth defects, as

436 determined by measuring bacterial density (Supplementary figure 2). Antimicrobial nanoparticles,

437 such as Ag nanoparticles, are antimicrobial as they interact with bacterial membranes and proteins

438 through the released metal cations (Sondi \& Salopek-Sondi, 2004). However, this effect seems to 
439 be minimal under our experimental conditions (Supplementary figure 2), likely due to the low

440 dissolution rate of $\mathrm{Ag}^{+}$cations (Lekamge et al. 2018). Ag nanoparticles had only a major effect on

441 bacterial density after five days compared to the other nanoparticles tested (Supplementary figure

442 2). The same was observed for $\mathrm{CuO}$ nanoparticles (Supplementary figure 2). Therefore, a constant 443 source of E. coli OP50 food, as determined by bacterial density, was available during the course 444 of the various experiments.

\section{Conclusions}

447 The aim of this study was to evaluate the effects of various nanoparticles on C. elegans using 448 standard phenotyping assays and characterize transcriptomics changes of the worms exposed to 449 selected nanoparticles (which showed the toxic effects for the majority of the parameters tested). 450 With all these observations, we provide a novel angle to study the toxicity of nanoparticles on 451 organisms, by exploring the mode of action of Ag and five metal oxide nanoparticles on different 452 life history endpoints in C. elegans. To the best of our knowledge, this is the first study that 453 integrates phenotype screening with RNAseq to investigate nanotoxicity in intact animals using $C$. 454 elegans. Our RNAseq data not only confirmed positive enrichment of apoptotic process as reported 455 in the literature (McShan, Ray \& Yu, 2014; Clement \& Jarrett, 1994; Kim et al., 2015) it also 456 revealed that toxicities induced by both nanoparticles have down-regulated genes in multiple 457 important regulatory biological processes and pathways, with opposite effects on innate immunity.

459 Additional Information and Declarations

\section{Funding}


461 This study was supported by the Fonds Québécois de la Recherche sur la Nature et les

462 Technologies (FQRNT), Genome Canada, Genome Quebec and the Natural Sciences and

463 Engineering Research Council of Canada (NSERC) Discovery Grant.

\section{Competing interests}

465 The authors declare that they have no competing interests.

\section{Author contributions}

467 This study was designed by C.V. and J.X. C.V. carried out the toxicity assays and related 468 statistical analysis and F.K. assisted with the wet laboratory work. RNAseq data analysis was 469 performed by O.H. J.X. supervised this study and C.V., O.H. and J.X. wrote this manuscript.

\section{Data availability}

471 The RNAseq dataset generated and analysed in this study is available in the NCBI Gene 472 Expression Omnibus (GEO) database repository, with the accession number GSE122728. 
473 Figure legends

474 Figure 1: Average locomotion velocity of adult day 1 C. elegans N2 after exposure to various 475 nanoparticles (A. Ag, B. $\mathrm{SiO}_{2}, \mathrm{C} . \mathrm{TiO}_{2}, \mathrm{D} . \mathrm{CeO}_{2}, \mathrm{E} . \mathrm{Al}_{2} \mathrm{O}_{3}$ and F. CuO) at 0,10 and $50 \mu \mathrm{gg} / \mathrm{ml}$. 476150 to $200 \mathrm{~L} 1 \mathrm{~s}$ were grown in 6-well plates containing S-medium supplemented with described 477 concentrations of each nanoparticle for $72 \mathrm{~h}$ at $21^{\circ} \mathrm{C}$. After washing and transferring the worms 478 onto an unseeded NGM plate, adult day 1 C. elegans were then video-recorded for $30 \mathrm{~s}$ using a 479 Nikon camera and average locomotion velocity was calculated using corresponding software for 480 every $0.500 \mathrm{msec}$ over the $30 \mathrm{~s}$ time span. Only $\mathrm{Ag}$ and $\mathrm{SiO} 2$ nanoparticles show significant 481 reductions in the velocity parameter at $10 \mu \mathrm{g} / \mathrm{ml}$ in comparison with control $(\mathrm{P} \leq 0.0001)$. Each 482 point represents a single worm. Statistical difference is indicated with an asterisk $(*)(* \mathrm{P}<0.05$, $483 * * \mathrm{P}<0.01, * * * \mathrm{P}=0.0001, * * * * \mathrm{P}<0.0001$ and $\mathrm{ns}:$ non-significant).

Figure 2: Body length of adult day 1 C. elegans $\mathrm{N} 2$ after exposure to various nanoparticles 485

(A. Ag, B. $\mathrm{SiO}_{2}$, C. $\mathrm{TiO}_{2}$, D. $\mathrm{CeO}_{2}, \mathrm{E} . \mathrm{Al}_{2} \mathrm{O}_{3}$ and $\mathrm{F} . \mathrm{CuO}$ ) at 0,10 and $50 \mu \mathrm{g} / \mathrm{ml} .200 \mathrm{~L}$ ls were 486 grown in 6-well plates containing S-medium supplemented with described concentrations of each 487 nanoparticle for $72 \mathrm{~h}$ at $21^{\circ} \mathrm{C}$. Worms were killed using $10 \mathrm{mM}$ sodium azide and transferred onto 488 an unseeded NGM plate. Worms were photographed using a Nikon camera and body length was 489 determined using corresponding software. All the nanoparticles except $\mathrm{TiO}_{2}$ demonstrated 490 reductions in the body length at $10 \mu \mathrm{g} / \mathrm{ml}$, compared to control $(\mathrm{P}<0.0001)$. Each point represents 491 a single worm.

Figure 3: Reproduction capacity of $C$. elegans N2 after exposure to various nanoparticles (A. young adult stage $\left(48 \mathrm{~h}\right.$ at $\left.21^{\circ} \mathrm{C}\right)$. Five L4-young adults were then transferred to a single well of a 
496

497

498

499

500

501

502

503

504

505

506

507

508

509

510

511

512

515

513 A downregulation pattern is observed in the $\mathrm{SiO}_{2}$ group, in comparison with the $\mathrm{Ag}$ group and 514 Control (A). Pink and blue circles in Venn diagram represents differentially expressed genes in

12-well plate containing S-medium with corresponding concentrations of nanoparticles $(0,10$ and $50 \mu \mathrm{g} / \mathrm{ml}$ ). Plates were then incubated for $96 \mathrm{~h}$ at $21^{\circ} \mathrm{C}$. The resulting total number of progeny was then calculated by dilution. $\mathrm{Ag}, \mathrm{SiO}_{2}$ and $\mathrm{CeO}_{2}$ nanoparticles reduced the reproduction capacity in comparison with control significantly at $10 \mu \mathrm{g} / \mathrm{ml}(\mathrm{P}<0.0001)$. Bar-graphs represent average brood size \pm standard deviation (SD) per five L4-young adult nematodes per condition.

Figure 4: Neurotoxicity of various nanoparticles (A. Ag, B. $\mathrm{SiO}_{2}, \mathrm{C}$. TiO, D. CeO, $\mathrm{E}_{2} \mathrm{Al}_{2} \mathrm{O}_{3}$ and F. CuO) to $C$. elegans $\mathbf{N 2}$ at $\mathbf{0 ,} 10$ and $50 \mu \mathrm{g} / \mathrm{ml} .200 \mathrm{~L} 1 \mathrm{~s}$ were grown in 6-well plates containing S-medium supplemented with described concentrations of each nanoparticle for $72 \mathrm{~h}$ at $21^{\circ} \mathrm{C}$. Adult day 1 worms were then washed and put into an unseeded NGM plate containing Kmedium and allowed to swim freely for $60 \mathrm{~s}$. The number of head thrashes made by a single worm were then counted for 1 minute. Only three nanoparticles, $\mathrm{CeO}_{2}, \mathrm{Al}_{2} \mathrm{O}_{3}$ and $\mathrm{CuO}$, show significant differences for the neurotoxicity parameter at $10 \mu \mathrm{g} / \mathrm{ml}$, compared to control $(\mathrm{P}<0.01)$. Bar-graphs represent average number of head thrashes \pm SD per condition.

Figure 5. Selected significant GO terms (detected by GSEA). Enriched BPs including regulation of locomotion, regulation of reproductive process and regulation of cell growth, show negative NES in the Ag group (A-C) and the $\mathrm{SiO} 2$ group (D-F) (FDR < 0.05).

Figure 6. Heatmap of differentially expressed genes involved in the innate immune response. the $\mathrm{SiO} 2$ and $\mathrm{Ag}$ groups, respectively (B). *: Ag, **: $\mathrm{SiO} 2, * * *$ : Common for $\mathrm{Ag}$ and $\mathrm{SiO} 2$. 
516 Figure 7. Selected significant KEGG pathways (detected by GSEA). Neuroactive ligand-

517 receptor interaction, wnt signaling pathway and MAPK signaling pathway, negatively enriched

518 based on NES, are shown in the Ag group (A-C) and the SiO2 group (D-F) (FDR < 0.05).

519 Figure 8. Proposed phenotype and transcriptome relationship in Ag and SiO2 toxicities. The

520 gene enrichment profiles of the biological processes and pathways are concordant with phenotype

521 characteristics for both toxicities. Arrows indicate gene enrichment profiles with negative or

522 positive manner. 
523 Tables

524 Table 1: Product details of six different nanoparticles. Each nanoparticle, used in this study, is

525 smaller than $100 \mathrm{~nm}$ in size. NA: non-applicable (no information provided from the suppliers).

526 Table 2. Top 20 and phenotype reflecting enriched biological processes. The enriched

527 biological processes, ranked based on NES and FDR value, are shown. The enriched biological

528 processes, detected by the GSEA analysis, were statistically significant (no asterisk: FDR <

529 0.0001, *: FDR $<0.05$ and **: FDR $<0.01)$. The phenotype reflecting enriched biological

530 processes are shown under dashed-line ${ }^{\ddagger}$ : Full name is provided in Supplementary data 2.

531 Table 3. Top 20 enriched biological pathways. Ranking of the enriched biological pathways is

532 based on NES and FDR value. The enriched biological pathways (KEGG) by the enrichment 533 analysis were found under statistically significant levels (FDR $<0.05)$ except those indicated with 534 asterisk (*: $0.05<\mathrm{P}<0.13 ; 0.12<\mathrm{FDR}<0.21)$. 


\section{Supplementary figures and data}

536 Supplementary figure 1: PCA analysis. Sample distribution for each toxicity group (in 537 comparison with control) is shown.

538 Supplementary figure 2: Effect of tested nanoparticles on E. coli OP50. E. coli OP50 was

539 grown in $50 \mu \mathrm{g} / \mathrm{ml}$ of $\mathrm{CeO}_{2}, \mathrm{Ag}, \mathrm{SiO}_{2}, \mathrm{TiO}_{2}, \mathrm{Al}_{2} \mathrm{O}_{3}$ and $\mathrm{CuO}$ nanoparticles in $\mathrm{S}$-medium in a 12-

540 well plate at $21^{\circ} \mathrm{C}$. Bacterial density was measured by taking the $\mathrm{OD}_{595 \mathrm{~nm}}$ values of three

541 independent wells. Statistical significance, after five days incubation, is indicated with an asterisk.

$542 * \mathrm{P}<0.05, * * * \mathrm{P}<0.01, * * * * \mathrm{P}<0.0001$, compared to E. coli OP50 alone.

543 Supplementary data 1. Differentially expressed genes by edgeR in the Ag and $\mathrm{SiO}_{2}$ groups.

544 A total of 2,648 genes were differentially expressed in the Ag group and a total of 1,087 genes

545 were differentially expressed in the $\mathrm{SiO} 2$ group, in comparison with Control (FDR $<0.05)$.

546 Supplementary data 2. Gene ontology enrichment by GSEA and GOATOOLS and newly

547 determined term enrichment by WormExp. Enriched biological processes showing up- and 548 down-regulation patterns are shown for both $\mathrm{Ag}$ and $\mathrm{SiO} 2$ groups $(\mathrm{P}<0.05)$. Genes with 549 description for the top 20 enriched biological processes are provided.

550 Supplementary data 3. KEGG pathway enrichment by GSEA. Enriched biological pathways

551 showing up- and down-regulation patterns are shown for the $\mathrm{Ag}$ and $\mathrm{SiO} 2$ groups $(\mathrm{P}<0.05)$. Genes

552 with description for the top 20 enriched biological pathways are provided. 


\section{References}

554 Alsaleh NB, Brown JM. 2018. Immune responses to engineered nanomaterials: current

555 understanding and challenges. Current opinion in toxicology 10, 8-14. doi:

$556 \quad 10.1016 / \mathrm{j} . \operatorname{cotox} \cdot 2017.11 .011$

557 Anbalagan C, Lafayette I, Antoniou-Kourounioti M, Haque M, King J, Johnsen B, Baillie D,

558 Gutierrez C, Martin JA, de Pomerai D. 2012. Transgenic nematodes as biosensors for metal 559 stress in soil pore water samples. Ecotoxicology 21(2):439-55. doi: 10.1007/s10646-011-0804-0.

560 Anders S, Pyl PT, Huber W. 2015. HTSeq-a Python framework to work with high-throughput 561 sequencing data. Bioinformatics 31(2), 166-169. doi: 10.1093/bioinformatics/btu638

Machado-Silva JR, Araujo N, Nacif-Pimenta R, Caffrey CR, Oliveira G. 2014. Regulation of

564 Schistosoma mansoni development and reproduction by the mitogen-activated protein kinase 565 signaling pathway. PLoS neglected tropical diseases 8(6), e2949. doi: 566 10.1371/journal.pntd.0002949

567 Bertani G. 1951. Studies on lysogenesis. I. The mode of phage liberation by lysogenic Escherichia 568 coli. Journal of bacteriology 62, 293-300.

569 Bianchi L, Kwok SM, Driscoll M, Sesti F. 2003. A potassium channel-MiRP complex controls 570 neurosensory function in Caenorhabditis elegans. The Journal of biological chemistry 278(14), 571 12415-12424. doi: 10.1074/jbc.M212788200

572 Bindea G, Mlecnik B, Hackl H, Charoentong P, Tosolini M, Kirilovsky A, Fridman WH, 573 Pagès F, Trajanoski Z, Galon J. 2009. ClueGO: a Cytoscape plug-in to decipher functionally 574 grouped gene ontology and pathway annotation networks. Bioinformatics 25(8), 1091-1093. doi: 575 10.1093/bioinformatics/btp101. 
576 Boraschi D, Italiani P, Palomba R, Decuzzi P, Duschl A, Fadeel B, Moghimi SM. 2017.

577 Nanoparticles and innate immunity: new perspectives on host defence. Seminars in immunology

578 34, 33-51. doi: 10.1016/j.smim.2017.08.013

579 Brenner S. 1974. The genetics of Caenorhabditis elegans. Genetics 77(1), 71-94.

580 Caito S, Fretham S, Martinez-Finley E, Chakraborty S, Avila D, Chen P, Aschner M. 2012.

581 Genome-Wide Analyses of Metal Responsive Genes in Caenorhabditis elegans. Front Genet 3:52.

582 doi: $10.3389 /$ fgene. 2012.00052

583 Capco, D. G (ed.)., Chen, Y (ed.). 2014. Nanomaterial Impacts on Cell Biology and Medicine

584811 (Springer, Dordrecht). https://doi.org/10.1007/978-94-017-8739-0

585 Carlson, M. 2018. org.Ce.eg.db: Genome wide annotation for Worm. R package version 3.6.0.

586 Clement JL, Jarrett PS. 1994. Antibacterial Silver. Metal-Based Drugs 1(5-6), 467-482. doi:

587 10.1155/MBD.1994.467

588 Cui Y, McBride SJ, Boyd WA, Alper S, Freedman JH. 2007. Toxicogenomic analysis of 589 Caenorhabditis elegans reveals novel genes and pathways involved in the resistance to cadmium 590 toxicity. Genome Biology 8(6):R122. doi:10.1186/gb-2007-8-6-r122

591 Dalpe G, Tarsitano M, Persico MG, Zheng H, Culotti J. 2013. C. elegans PVF-1 inhibits 592 permissive UNC-40 signalling through CED-10 GTPase to position the male ray 1 sensillum. 593 Development 140(19), 4020-4030. doi: 10.1242/dev.095190

594 Dekkers S, Krystek P, Peters RJ, Lankveld DP, Bokkers BG, van Hoeven-Arentzen PH,

595 Bouwmeester H, Oomen AG. 2011. Presence and risks of nanosilica in food products. 596 Nanotoxicology 5(3):393-405. doi: 10.3109/17435390.2010.519836. 
597 Dernovici S, Starc T, Dent JA, Ribeiro P. 2007. The serotonin receptor SER-1 (5HT2ce)

598 contributes to the regulation of locomotion in Caenorhabditis elegans. Developmental 599 neurobiology 67(2), 189-204. doi: 10.1002/dneu.20340

600 Djurišić AB, Leung YH, Ng AM, Xu XY, Lee PK., Degger N, Wu RS. 2015. Toxicity of metal 601 oxide nanoparticles: mechanisms, characterization, and avoiding experimental artefacts. Small 602 11(1), 26-44. doi: 10.1002/smll.201303947

603 Fang-Yen C, Avery L, Samuel ADT. 2009. Two size-selective mechanisms specificallytrap 604 bacteria-sized food particles in Caenorhabditis elegans. Proceedings of the National Academy of 605 Sciences of the United States of America 106(47), 20093-20096, doi:10.1073/pnas.0904036106

606 Fröhlich E, Roblegg E. 2016. Oral uptake of nanoparticles: human relevance and the role of in 607 vitro systems. Archives of Toxicology 90(10):2297-2314. doi: 10.1007/s00204-016-1765-0.

608 Gao J, Wang Y, Hovsepyan A, Bonzongo JC. 2011. Effects of engineered nanomaterials on 609 microbial catalyzed biogeochemical processes in sediments. Journal of Hazardous Materials 610 186(1), 940-945, doi: 10.1016/j.jhazmat.2010.11.084

611 Gracida X, Eckmann CR. 2013. Fertility and germline stem cell maintenance under different 612 diets requires nhr-114/HNF4 in C. elegans. Current Biology. 23(7), 607-613. doi: $613 \quad 10.1016 /$ j.cub.2013.02.034.

614 Hernandez Gifford JA. 2015. The role of WNT signaling in adult ovarian folliculogenesis. 615 Reproduction 150(4), R137-148. doi: 10.1530/REP-14-0685

616 Inoki K, Ouyang H, Zhu T, Lindvall C, Wang Y, Zhang X, Yang Q, Bennett C, Harada Y, 617 Stankunas K, Wang CY, He X, MacDougald OA, You M, Williams BO, Guan KL. 2006. 618 TSC2 integrates Wnt and energy signals via a coordinated phosphorylation by AMPK and GSK3 619 to regulate cell growth. Cell 126(5), 955-968. doi: 10.1016/j.cell.2006.06.055 
620 Jung SK, Qu X, Aleman-Meza B, Wang T, Riepe C, Liu Z, Li Q, Zhong W. 2015. Multi-

621 endpoint, high-throughput study of nanomaterial toxicity in Caenorhabditis elegans.

622 Environmental science \& technology 49(4), 2477-85. doi: 10.1021/es5056462

623 Kaletta T, Hengartner MO. 2006. Finding function in novel targets: C. elegans as a model 624 organism. Nature reviews. Drug discovery 5(5), 387-398.

625 Khanna P, Ong C, Bay BH, Baeg GH. 2015. Nanotoxicity: An Interplay of Oxidative Stress, 626 Inflammation and Cell Death. Nanomaterials (Basel) 5(3), 1163-1180. doi: 10.3390/nano5031163

627 Kim D, Langmead B, Salzberg SL. 2015. HISAT: a fast spliced aligner with low memory 628 requirements. Nature methods 12(4), 357-360. doi: 10.1038/nmeth.3317

629 Kim IY, Joachim E, Choi H, Kim K. 2015. Toxicity of silica nanoparticles depends on size, 630 dose, and cell type. Nanomedicine 11(16), 1407-1416. doi: 10.1016/j.nano.2015.03.004

631 Kleiven M, Rossbach LM, Gallego-Urrea JA, Brede DA, Oughton DH, Coutris C. 2018. 632 Characterizing the behavior, uptake, and toxicity of NM300K silver nanoparticles in 633 Caenorhabditis elegans. Environmental toxicology and chemistry 37(7), 1799-1810. doi: 63410.1002 /etc.4144

635 Klopfenstein DV, Zhang L, Pedersen BS, Ramírez F, Warwick Vesztrocy A, Naldi A, 636 Mungall CJ, Yunes JM, Botvinnik O, Weigel M, Dampier W, Dessimoz C, Flick P, Tang H. 637 2018. GOATOOLS: A Python library for Gene Ontology analyses. Scientific reports 8(1):10872. 638 doi: 10.1038/s41598-018-28948-z.

639 Knutson AK, Egelhofer T, Rechtsteiner A, Strome S. 2017. Germ Granules Prevent 640 Accumulation of Somatic Transcripts in the Adult Caenorhabditis elegans Germline. Genetics, 641 206(1), 163-178. doi: 10.1534/genetics.116.198549. 
642 Komatsu H, Mori I, Rhee JS, Akaike N, Ohshima Y. 1996. Mutations in a cyclic nucleotide-

643 gated channel lead to abnormal thermosensation and chemosensation in C. elegans. Neuron 17(4), $644 \quad 707-18$

645 Kong Y, Liang X, Liu L, Zhang D, Wan C, Gan Z, Yuan L. 2015. High Throughput Sequencing 646 Identifies MicroRNAs Mediating $\alpha$-Synuclein Toxicity by Targeting Neuroactive-Ligand 647 Receptor Interaction Pathway in Early Stage of Drosophila Parkinson's Disease Model. PLoS One 648 10(9), e0137432. doi: 10.1371/journal.pone.0137432

649 Kumar R, Pradhan A, Khan FA, Lindström P, Ragnvaldsson D, Ivarsson P, Olsson 650 PE, Jass J. 2015. Comparative Analysis of Stress Induced Gene Expression in Caenorhabditis 651 elegans following Exposure to Environmental and Lab Reconstituted Complex Metal Mixture.

652 PLoS One 10(7):e0132896. doi: 10.1371/journal.pone.0132896

653 Lekamge S, Miranda AF, Abraham A, Li V, Shukla R, Bansal V and Nugegoda D. 2018. The 654 Toxicity of Silver Nanoparticles (AgNPs) to Three Freshwater Invertebrates With Different Life 655 Strategies: Hydra vulgaris, Daphnia carinata, and Paratya australiensis. Frontiers in 656 Environmental Science 6, 152 doi: 10.3389/fenvs.2018.00152

657 Lewis JA, Fleming JT. 1995. Basic culture methods. Methods in cell biology 48, 3-29.

658 Li H, Handsaker B, Wysoker A, Fennell T, Ruan J, Homer N, Marth G, Abecasis G, Durbin 659 R; 1000 Genome Project Data Processing Subgroup. 2009. The Sequence Alignment/Map 660 format and SAMtools. Bioinformatics 25(16), 2078-2079. doi: 10.1093/bioinformatics/btp352

661 Luo W, Friedman MS, Shedden K, Hankenson KD, Woolf PJ. 2009. GAGE: generally 662 applicable gene set enrichment for pathway analysis. BMC Bioinformatics 10, 161. doi: $66310.1186 / 1471-2105-10-161$. 
664 Mayer MP, Bukau B. 2005. Hsp70 chaperones: cellular functions and molecular mechanism.

665 Cellular and molecular life sciences : CMLS 62(6), 670-684. doi: 10.1007/s00018-004-4464-6

666 Mayer S, Raulf MK, Lepenies B. 2017. C-type lectins: their network and roles in pathogen

667 recognition and immunity. Histochemistry and cell biology 147(2), 223-237. doi: 10.1007/s00418-

$668 \quad 016-1523-7$

669 Maynard, AD. 2011. Don't define nanomaterials. Nature 475(7354), 31. doi: 10.1038/475031a 670 (2011).

671 McShan D, Ray PC, Yu H. 2014. Molecular toxicity mechanism of nanosilver. Journal of food 672 and drug analysis 22(1), 116-127. doi: 10.1016/j.jfda.2014.01.010

673 Medina C, Santos-Martinez MJ, Radomski A, Corrigan OI, Radomski MW. 2007.

674 Nanoparticles: pharmacological and toxicological significance. British journal of pharmacology

675 150(5), 552-558. doi: 10.1038/sj.bjp.0707130

676 National Research Council. 2000. Scientific Frontiers in Developmental Toxicology and Risk 677 Assessment. Committee on Developmental Toxicology, Board on Environmental Studies and 678 Toxicology. National Academies Press (US). National Academy of Sciences. Washington (DC).

679 Nayak S, Santiago FE, Jin H, Lin D, Schedl T, Kipreos ET. 2002. The Caenorhabditis elegans 680 Skp1-related gene family: diverse functions in cell proliferation, morphogenesis, and meiosis. 681 Current biology 12(4), 277-287.

682 Oberdörster G. 2010. Safety assessment for nanotechnology and nanomedicine: concepts of 683 Nanotoxicology. Journal of internal medicine 267(1), 89-105. doi: 10.1111/j.1365684 2796.2009.02187.x

685 Pennefather JN. 2004. Tachykinins and tachykinin receptors: a growing family. Life sciences $68674(12), 1445-1463$. 
687 Piechulek AA, von Mikecz A. 2018. Life span-resolved nanotoxicology enables identification of 688 age-associated neuromuscular vulnerabilities in the nematode Caenorhabditis elegans. 689 Environmental pollution 233, 1095-1103. doi: 10.1016/j.envpol.2017.10.012

690 Piechulek AA, Berwanger LC, von Mikecz. 2019. Silica nanoparticles disrupt OPT-2/PEP-2691 dependent trafficking of nutrient peptides in the intestinal epithelium. Nanotoxicology 13(8), 1133692 1148. doi: 10.1080/17435390.2019.1643048

693 Pluskota A, Horzowski E, Bossinger O, von Mikecz A. 2009. In Caenorhabditis elegans 694 nanoparticle-bio-interactions become transparent: silica-nanoparticles induce reproductive 695 senescence. PLoS One 4(8), e6622. doi: 10.1371/journal.pone.0006622

696 Powell JA. 2014. GO2MSIG, an automated GO based multi-species gene set generator for gene 697 set enrichment analysis. BMC Bioinformatics 15:146. doi: 10.1186/1471-2105-15-146

698 Robinson MD, McCarthy DJ, Smyth GK. 2010. edgeR: a Bioconductor package for differential 699 expression analysis of digital gene expression data. Bioinformatics 26(1), 139-140. doi: 700 10.1093/bioinformatics/btp616

701 Rocheleau S, Arbour M, Elias M, Sunahara GI, Masson L. 2015. Toxicogenomic effects of 702 nano- and bulk-TiO2 particles in the soil nematode Caenorhabditis elegans. Nanotoxicology 9(4), 703 502-512. doi: 10.3109/17435390.2014.948941

704 Roh JY, Lee J, Choi J. 2006. Assessment of stress-related gene expression in the heavy metal705 exposed nematode Caenorhabditis elegans: a potential biomarker for metal-induced toxicity 706 monitoring and environmental risk assessment. Environ Toxicol Chem 25(11):2946-56. doi: 707 10.1897/05-676r. 1 
708

709

710

711

712

713

714

715

716

717

718

719

720

721

722

723

724

725

726

727

728

729

730

Roubin R, Naert K, Popovici C, Vatcher G, Coulier F, Thierry-Mieg J, Pontarotti P,

Birnbaum D, Baillie D, Thierry-Mieg D. 1999. let-756, a C. elegans fgf essential for worm development. Oncogene 18(48), 6741-6747. doi: 10.1038/sj.onc.1203074

Ruiz-Lancheros E, Viau C, Walter TN, Francis A, Geary TG. 2011. Activity of novel nicotinic anthelmintics in cut preparations of Caenorhabditis elegans. International journal for parasitology 41(3-4), 455-461. doi: 10.1016/j.ijpara.2010.11.009

Scheel J, Srinivasan J, Honnert U, Henske A, Kurzchalia TV. 1999. Involvement of caveolin-1 in meiotic cell-cycle progression in Caenorhabditis elegans. Nature cell biology 1(2), 127-129. doi: $10.1038 / 10100$

Shannahan J. 2017. The biocorona: a challenge for the biomedical application of nanoparticles. Nanotechnology reviews 6(4), 345-353. doi: 10.1515/ntrev-2016-0098

Scharf A, Gührs KH, von Mikecz A. 2016. Anti-amyloid compounds protect from silica nanoparticle-induced neurotoxicity in the nematode C. elegans. Nanotoxicology 10(4):426-435. doi: 10.3109/17435390.2015.1073399.

Simeone FC, Costa AL. 2019. Assessment of cytotoxicity of metal oxide nanoparticles on the basis of fundamental physical-chemical parameters: a robust approach to grouping. Environmental Science: Nano 6, 3102-3112. doi: 10.1039/c9en00785g

Sondi I, Salopek-Sondi B. 2004. Silver nanoparticles as antimicrobial agent: a case study on $E$. coli as a model for Gram-negative bacteria. Journal of Colloid and Interface Science 275(1):177182. doi: $10.1016 /$ j.jcis.2004.02.012

Sonowal R, Swimm A, Sahoo A, Luo L, Matsunaga Y, Wu Z, Bhingarde JA, Ejzak EA, Ranawade A, Qadota H, Powell DN, Capaldo CT, Flacker JM, Jones RM, Benian GM, Kalman D. 2017. Indoles from commensal bacteria extend healthspan. Proceedings of the 
731 National Academy of Sciences of the United States of America 114(36), E7506-E7515.

732 doi:10.1073/pnas.1706464114

733 Staab TA, Griffen TC, Corcoran C, Evgrafov O, Knowles JA, Sieburth D. 2013. The

734 conserved SKN-1/Nrf2 stress response pathway regulates synaptic function in Caenorhabditis

735 elegans. PLoS Genetics 9(3):e1003354. doi: 10.1371/journal.pgen.1003354.

736 Starnes DL, Lichtenberg SS, Unrine JM, Starnes CP, Oostveen EK, Lowry GV, Bertsch PM,

737 Tsyusko OV. 2016. Distinct transcriptomic responses of Caenorhabditis elegans to pristine and 738 sulfidized silver nanoparticles. Environmental pollution 213, 314-321. doi: 739 10.1016/j.envpol.2016.01.020

740 Stiernagle T. 2006. Maintenance of $C$. elegans. WormBook, 2006, 1-11. doi: 741 10.1895/wormbook.1.101.1

742 Subramanian A, Tamayo P, Mootha VK, Mukherjee S, Ebert BL, Gillette MA, Paulovich A,

743 Pomeroy SL, Golub TR, Lander ES, Mesirov JP. 2005. Gene set enrichment analysis: a 744 knowledge-based approach for interpreting genome-wide expression profiles. Proceedings of the 745 National Academy of Sciences of the United States of America 102(43), 15545-50. 746 doi:10.1073/pnas.0506580102

747 Sulston J, Hodgkin J. 1988. Methods. In 'The nematode Caenorhabditis elegans'.(Ed. Wood,W.

748 B.) 587-606 (Cold Spring Harbor Laboratory Press: Plainview).

749 Tsalik EL, Hobert O. 2003. Functional mapping of neurons that control locomotory behavior in 750 Caenorhabditis elegans. Journal of neurobiology 56(2), 178-197. doi: 10.1002/neu.10245

751 Uchida O, Nakano H, Koga M, Ohshima Y. 2003. The $C$. elegans che-1 gene encodes a zinc

752 finger transcription factor required for specification of the ASE chemosensory neurons. 753 Development 130(7), 1215-1224. 
754 Warner DR., Greene RM, Pisano MM. 2005. Cross-talk between the TGFbeta and Wnt

755 signaling pathways in murine embryonic maxillary mesenchymal cells. FEBS letters 579(17), 756 3539-3546. doi: 10.1016/j.febslet.2005.05.024

757 Wu Q, Nouara A, Li Y, Zhang M, Wang W, Tang M, Ye B, Ding J, Wang D. 2013.

758 Comparison of toxicities from three metal oxide nanoparticles at environmental relevant 759 concentrations in nematode Caenorhabditis elegans. Chemosphere 90(3), 1123-1131. doi: 760 10.1016/j.chemosphere.2012.09.019

761 Yang W, Dierking K, Schulenburg H. 2016. WormExp: a web-based application for a 762 Caenorhabditis elegans-specific gene expression enrichment analysis. Bioinformatics 32(6):943763 5. doi: 10.1093/bioinformatics/btv667

764 Zhang W, Liu HT. 2002. MAPK signal pathways in the regulation of cell proliferation in 765 mammalian cells. Cell research 12(1), 9-18. doi: 10.1038/sj.cr.7290105

766 Zhou G, Soufan O, Ewald J, Hancock REW, Basu N, Xia J. 2019. NetworkAnalyst 3.0: a visual 767 analytics platform for comprehensive gene expression profiling and meta-analysis. Nucleic Acids 768 Research. 47(W1):W234-W241. doi: 10.1093/nar/gkz240 


\section{Table $\mathbf{1}$ (on next page)}

Product details of six different nanoparticles

Each nanoparticle, used in this study, is smaller than $100 \mathrm{~nm}$ in size. NA: non-applicable (no information provided from the suppliers). 
Table 1. Product details of six different nanoparticles

\begin{tabular}{llllll}
\hline Nanoparticle & Symbol & Catalog number/Brand & CAS Number & Size (nm) & Shape \\
\hline Silver & $\mathrm{Ag}$ & 576832/Aldrich & $7440-22-4$ & $<100$ & Spherical \\
Silicon dioxide & $\mathrm{SiO}_{2}$ & 637238/Aldrich & $7631-86-9$ & $10-20$ (BET) & Spherical \\
Cerium(IV) oxide & $\mathrm{CeO}_{2}$ & 544841/Aldrich & $1306-38-3$ & $<25(\mathrm{BET})$ & NA \\
Copper(II) oxide & $\mathrm{CuO}$ & $544868 /$ Aldrich & $1317-38-0$ & $<50(\mathrm{TEM})$ & NA \\
Aluminum oxide & $\mathrm{Al}_{2} \mathrm{O}_{3}$ & 544833/Aldrich & $1344-28-1$ & $<50(\mathrm{TEM})$ & NA \\
Titanium dioxide & $\mathrm{TiO}_{2}$ & NM-101/JRC & NA & 8 & NA
\end{tabular}




\section{Table 2 (on next page)}

Top 20 and phenotype reflecting enriched biological processes.

The enriched biological processes, ranked based on NES and FDR value, are shown. The enriched biological processes, detected by the GSEA analysis, were statistically significant (no asterisk: FDR $<0.0001$, *: FDR $<0.05$ and **: FDR $<0.01$ ). The phenotype reflecting enriched biological processes are shown under dashed-line ${ }^{\ddagger}$ : Full name is provided in Supplementary data 2 . 
Table 2. Top 20 and phenotype reflecting enriched biological processes

\begin{tabular}{|c|c|c|c|c|c|c|c|}
\hline & & Ag & & & $\mathrm{SiO2}$ & & \\
\hline & Biological process & & NES & Rank & & NES & Rank \\
\hline \multicolumn{8}{|l|}{ Positive enrichment } \\
\hline & Cellular process & Cell cycle & 6.591 & 2 & Cell cycle & 4.095 & 2 \\
\hline & & Cell cycle process & 6.624 & 1 & Cell cycle process & 4.167 & 1 \\
\hline & & Meiotic cell cycle & 5.455 & 10 & Meiotic cell cycle & 3.413 & 10 \\
\hline & & Meiotic cell cycle process & 4.744 & 15 & _- & - & _- \\
\hline & & Meiotic nuclear division & 5.215 & 12 & Meiotic nuclear division & 3.158 & 12 \\
\hline & & Meiotic chromosome segregation & 4.441 & 18 & - & - & _ \\
\hline & & Mitotic cell cycle & 4.805 & 14 & Mitotic cell cycle & 2.776 & 19 \\
\hline & & Regulation of cell cycle & 4.378 & 20 & _ & - & - \\
\hline & & Cell division & 4.561 & 17 & Cell division & 2.886 & 14 \\
\hline & & Death\&cell death & 6.022 & 4 & Death\&cell death & 3.699 & 7 \\
\hline & & Programmed cell death & 5.736 & 7 & Programmed cell death & 3.695 & 8 \\
\hline & & Apoptotic process & 6.332 & 3 & Apoptotic process & 3.887 & 5 \\
\hline & & Chromosome segregation & 4.943 & 13 & - & - & - \\
\hline & & Posttranscriptional gene silencing\&gene silencing & 4.407 & 19 & _ & _- & _- \\
\hline & Growth & - & - & - & Developmental growth & 2.771 & 20 \\
\hline & & - & - & - & Regulation of growth & 2.787 & 18 \\
\hline & $\begin{array}{l}\text { Metabolic process } \\
\text { Multicellular organism }\end{array}$ & Posttranscriptional regulation of gene gene expression ${ }^{\dagger}$ & 4.571 & 16 & 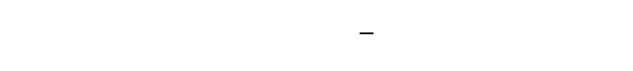 & - & - \\
\hline & process & _ & - & _- & Positive regulation of multicellular organismal process & 2.814 & 16 \\
\hline & Multi-organism process & Sexual reproduction & 5.713 & 8 & Sexual reproduction & 3.854 & 6 \\
\hline & & Gamete generation & 5.982 & 5 & Gamete generation & 4.012 & 3 \\
\hline & & Germ cell development\&cellular process ${ }^{\ddagger}$ & 5.334 & 11 & Germ cell development\& cellular process ${ }^{\dagger}$ & 3.897 & 4 \\
\hline & & - & - & - & Female gamete generation & 2.813 & 17 \\
\hline & & - & - & - & Oogenesis & 3.010 & 13 \\
\hline & & - & _ & _ & Spermatid differentiation\& spermatid development & 2.818 & 15 \\
\hline & $\begin{array}{l}\text { Cellular component } \\
\text { organization or biogenesis }\end{array}$ & Organelle fission & 5.756 & 6 & Organelle fission & 3.433 & 9 \\
\hline & & Nuclear division & 5.621 & 9 & Nuclear division & 3.364 & 11 \\
\hline \multicolumn{8}{|l|}{ Negative enrichment } \\
\hline & Behavior & Single organism behavior & -4.631 & 1 & - & - & _- \\
\hline & Cellular process & Cell communication & -4.285 & 7 & Aromatic compound biosynthetic process & -5.477 & 11 \\
\hline & & Cell surface receptor signaling pathway & -4.082 & 17 & Regulation of cellular metabolic process & -5.198 & 19 \\
\hline & Developmental process & Cell morphogenesis & -4.571 & 3 & - & - & - \\
\hline & & Cell projection morphogenesis & -4.576 & 2 & - & - & - \\
\hline & & Cell part morphogenesis & -4.276 & 8 & - & _- & _- \\
\hline & & Generation of neurons & -4.048 & 20 & _ & _ & _ \\
\hline
\end{tabular}


Table 2. continued

Metabolic process

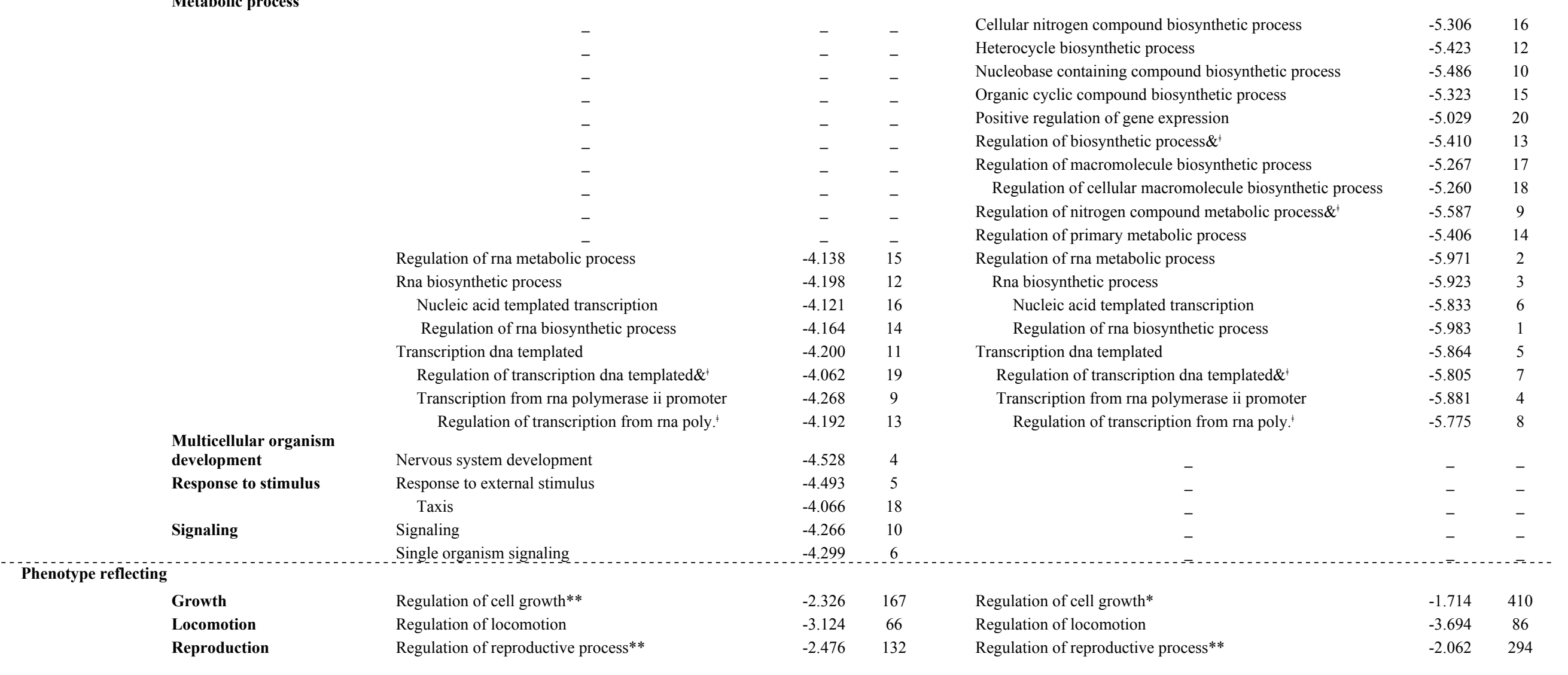




\section{Table 3 (on next page)}

Top 20 enriched biological pathways.

Ranking of the enriched biological pathways is based on NES and FDR value. The enriched biological pathways (KEGG) by the enrichment analysis were found under statistically significant levels (FDR $<0.05$ ) except those indicated with asterisk $(*: 0.05<P<0.13 ; 0.12$ $<$ FDR $<0.21$ ). 
Table 3. Top 20 enriched biological pathways

\begin{tabular}{|c|c|c|c|c|c|c|}
\hline \multicolumn{4}{|c|}{ Ag } & \multicolumn{3}{|l|}{$\mathrm{SiO2}$} \\
\hline & Biological pathway & NES & Rank & Biological pathway & NES & Rank \\
\hline \multirow[t]{20}{*}{ Positive enrichment } & Ribosome & 7.179 & 1 & Ribosome & 6.864 & 1 \\
\hline & Proteasome & 4.731 & 2 & Proteasome & 3.682 & 2 \\
\hline & Rna transport & 4.484 & 3 & Aminoacyl-trna biosynthesis & 3.296 & 3 \\
\hline & Spliceosome & 4.453 & 4 & Oxidative phosphorylation & 2.986 & 4 \\
\hline & Oxidative phosphorylation & 4.320 & 5 & Carbon metabolism & 2.969 & 5 \\
\hline & Aminoacyl-trna biosynthesis & 4.078 & 6 & Rna transport & 2.955 & 6 \\
\hline & Ribosome biogenesis in eukaryotes & 3.661 & 7 & Pyruvate metabolism & 2.724 & 7 \\
\hline & Nucleotide excision repair & 3.643 & 8 & Rna polymerase & 2.439 & 8 \\
\hline & Carbon metabolism & 3.458 & 9 & Fanconi anemia pathway & 2.337 & 9 \\
\hline & Glycosylphosphatidylinositol (gpi)-anchor biosynthesis & 3.349 & 10 & Ribosome biogenesis in eukaryotes & 2.333 & 10 \\
\hline & Fanconi anemia pathway & 3.330 & 11 & Fatty acid metabolism & 2.280 & 11 \\
\hline & Dna replication & 3.316 & 12 & Nucleotide excision repair & 2.170 & 12 \\
\hline & Pyrimidine metabolism & 3.141 & 13 & Pyrimidine metabolism & 2.169 & 13 \\
\hline & Rna polymerase & 3.021 & 14 & Fatty acid degradation & 2.160 & 14 \\
\hline & Mrna surveillance pathway & 2.926 & 15 & Rna degradation & 2.157 & 15 \\
\hline & Endocytosis & 2.840 & 16 & Valine, leucine and isoleucine degradation & 2.144 & 16 \\
\hline & Rna degradation & 2.816 & 17 & Biosynthesis of amino acids & 2.140 & 17 \\
\hline & Mismatch repair & 2.762 & 18 & Glycosylphosphatidylinositol (gpi)-anchor biosynthesis & 2.087 & 18 \\
\hline & Homologous recombination & 2.747 & 19 & Dna replication & 2.066 & 19 \\
\hline & Peroxisome & 2.699 & 20 & Glycolysis / gluconeogenesis & 2.065 & 20 \\
\hline & Neuroactive ligand-receptor interaction & -2.490 & 1 & Protein processing in endoplasmic reticulum & -3.896 & 1 \\
\hline & Wnt signaling pathway & -2.350 & 2 & Endocytosis & -3.374 & 2 \\
\hline & Lysosome & -2.199 & 3 & Spliceosome & -3.298 & 3 \\
\hline & Ecm-receptor interaction & -2.180 & 4 & Wnt signaling pathway & -3.199 & 4 \\
\hline & Phagosome & -2.118 & 5 & Ubiquitin mediated proteolysis & -2.849 & 5 \\
\hline & Mapk signaling pathway & -1.973 & 6 & Tgf-beta signaling pathway & -2.782 & 6 \\
\hline
\end{tabular}


Table 3. continued

Calcium signaling pathway

Drug metabolism - cytochrome $\mathrm{p} 450$

Autophagy - animal

Age-rage signaling pathway in diabetic complications

Tgf-beta signaling pathway

Glycosphingolipid biosynthesis - globo and isoglobo series

Erbb signaling pathway

Polyketide sugar unit biosynthesis

Taurine and hypotaurine metabolism*

Glycosaminoglycan degradation*

Autophagy - other*

Hippo signaling pathway -multiple species*

Retinol metabolism*

Mitophagy - animal*

$\begin{array}{lll}-1.921 & 7 & \text { Mrna surveillance pathway } \\ -1.872 & 8 & \text { Mapk signaling pathway } \\ -1.726 & 9 & \text { Calcium signaling pathway } \\ -1.713 & 10 & \text { Ecm-receptor interaction } \\ -1.667 & 11 & \text { Phosphatidylinositol signaling system } \\ -1.593 & 12 & \text { Notch signaling pathway } \\ -1.590 & 13 & \text { Autophagy - other } \\ -1.589 & 14 & \text { Hippo signaling pathway -multiple species } \\ -1.601 & 15 & \text { Autophagy - animal } \\ -1.578 & 16 & \text { Inositol phosphate metabolism } \\ -1.450 & 17 & \text { Neuroactive ligand-receptor interaction } \\ -1.433 & 18 & \text { Phagosome } \\ -1.413 & 19 & \text { Mitophagy - animal } \\ -1.376 & 20 & \text { Basal transcription factors }\end{array}$

$\begin{array}{ll}-2.738 & 7 \\ -2.600 & 8 \\ -2.248 & 9 \\ -2.077 & 10 \\ -2.068 & 11 \\ -1.951 & 12 \\ -1.946 & 13 \\ -1.913 & 14 \\ -1.866 & 15 \\ -1.839 & 16 \\ -1.828 & 17 \\ -1.816 & 18 \\ -1.804 & 19 \\ -1.700 & 20\end{array}$




\section{Figure 1}

Average locomotion velocity of adult day $1 \mathrm{C}$. elegans N2 after exposure to various nanoparticles (A. Ag, B. $\mathrm{SiO}_{2}, \mathrm{C} . \mathrm{TiO}_{2}$, D. $\mathrm{CeO}_{2}, \mathrm{E} . \mathrm{Al}_{2} \mathrm{O}_{3}$ and F. CuO) at 0, 10 and 50 $\mu \mathrm{g} / \mathrm{ml}$.

200 L1s were grown in 6-well plates containing S-medium supplemented with described concentrations of each nanoparticle for $72 \mathrm{~h}$ at $21^{\circ} \mathrm{C}$. After washing and transferring the worms onto an unseeded NGM plate, adult day 1 C. elegans were then video-recorded for 30 s using a Nikon camera and average locomotion velocity was calculated using corresponding software for every 0.500 msec over the 30 s time span. Only Ag and SiO2 nanoparticles show significant reductions in the velocity parameter at $10 \mu \mathrm{g} / \mathrm{ml}$ in comparison with control $(\mathrm{P}<$ 0.0001). Each point represents a single worm. Statistical difference is indicated with an asterisk $(*)\left(* \mathrm{P}<0.05,{ }^{*} \mathrm{P}<0.01,{ }^{* * * \mathrm{P}}=0.0001,{ }^{* * * * \mathrm{P}}<0.0001\right.$ and ns: non-significant). 


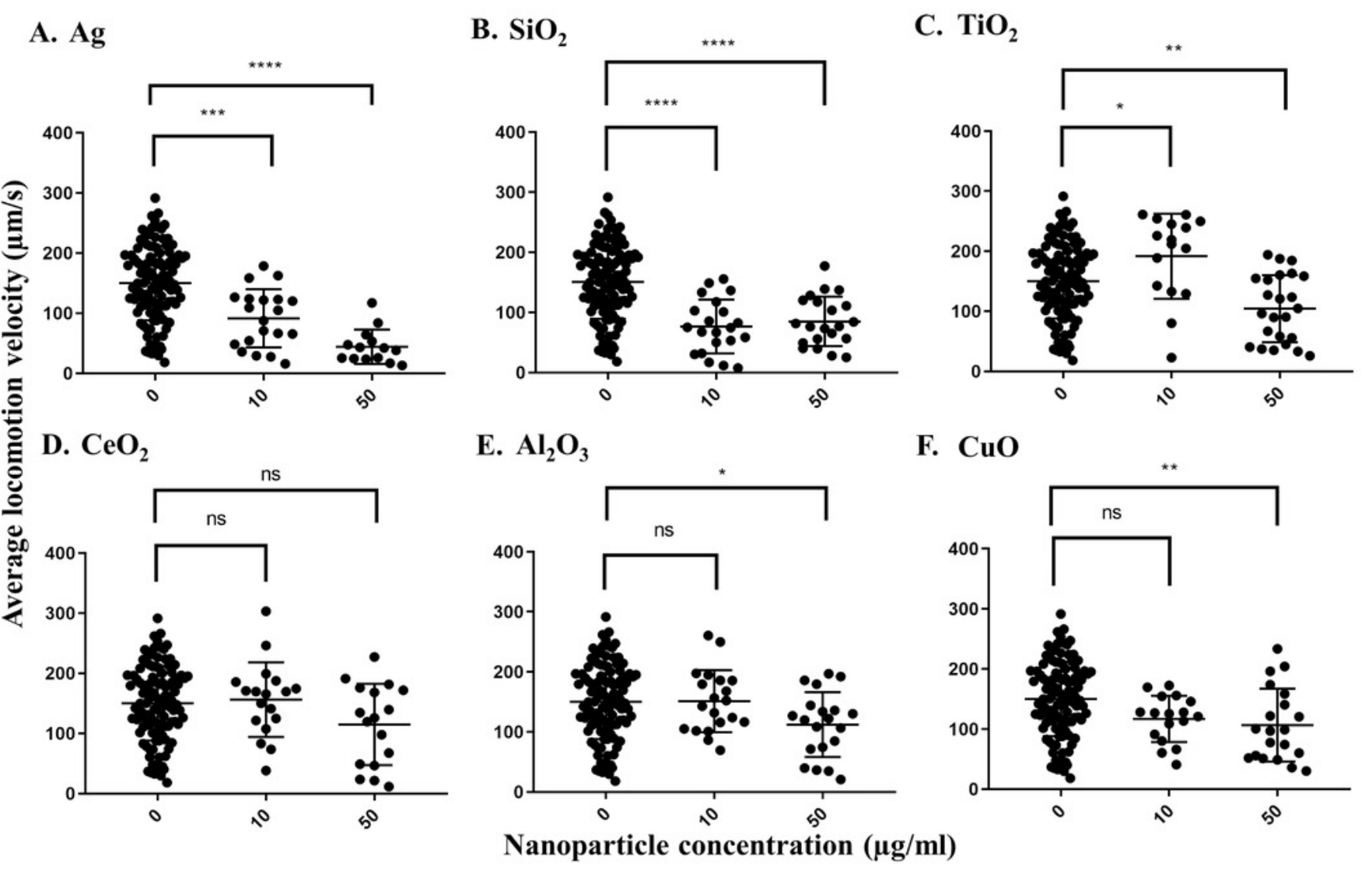




\section{Figure 2}

Body length of adult day $1 C$. elegans N2 after exposure to various nanoparticles ( $A . A g$, B. $\mathrm{SiO}_{2}, \mathrm{C} . \mathrm{TiO}_{2}, \mathrm{D} . \mathrm{CeO}_{2}, \mathrm{E} . \mathrm{Al}_{2} \mathrm{O}_{3}$ and F. CuO) at 0,10 and $50 \mu \mathrm{g} / \mathrm{ml}$.

200 L1s were grown in 6-well plates containing S-medium supplemented with described concentrations of each nanoparticle for $72 \mathrm{~h}$ at $21^{\circ} \mathrm{C}$. Worms were killed using $10 \mathrm{mM}$ sodium azide and transferred onto an unseeded NGM plate. Worms were photographed using a Nikon camera and body length was determined using corresponding software. All the nanoparticles except $\mathrm{TiO}_{2}$ demonstrated reductions in the body length at $10 \mu \mathrm{g} / \mathrm{ml}$, compared to control (P $<0.0001$ ). Each point represents a single worm.

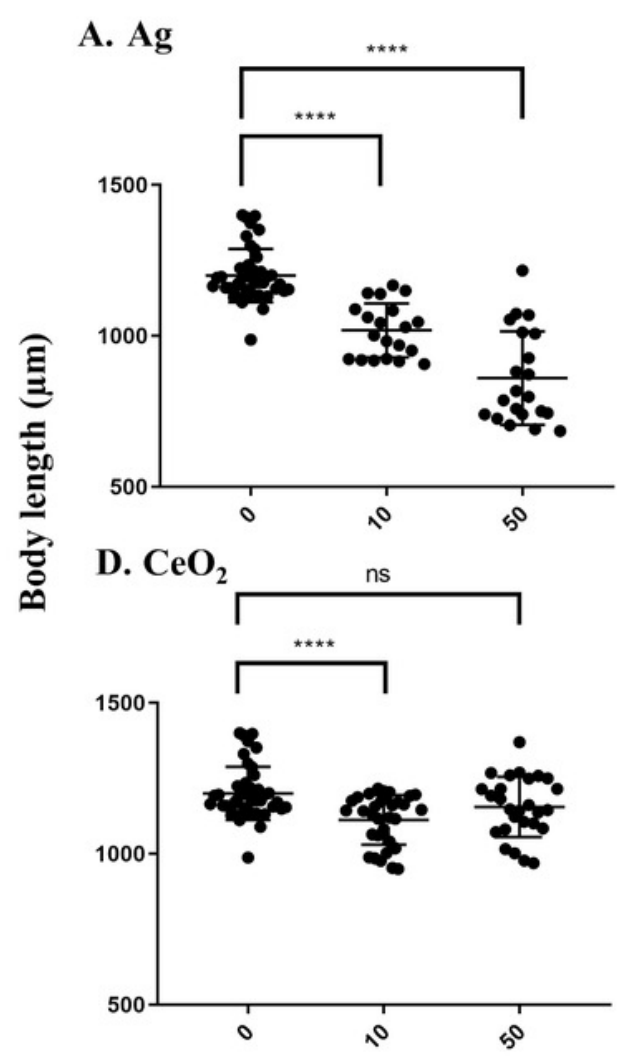

B. $\mathrm{SiO}_{2}$

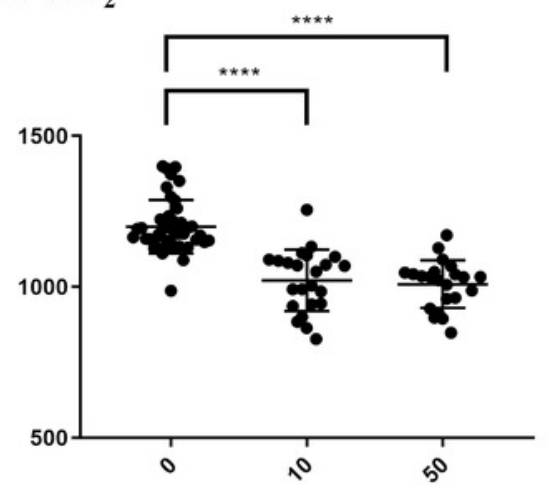

E. $\mathrm{Al}_{2} \mathrm{O}_{3}$

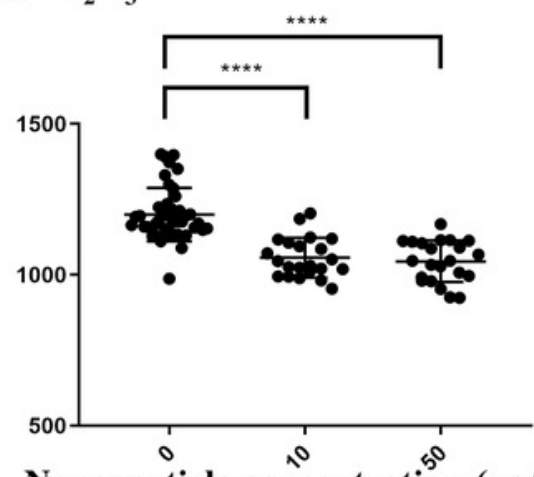

Nanoparticle concentration $(\mu \mathrm{g} / \mathrm{ml})$
C. $\mathrm{TiO}_{2}$

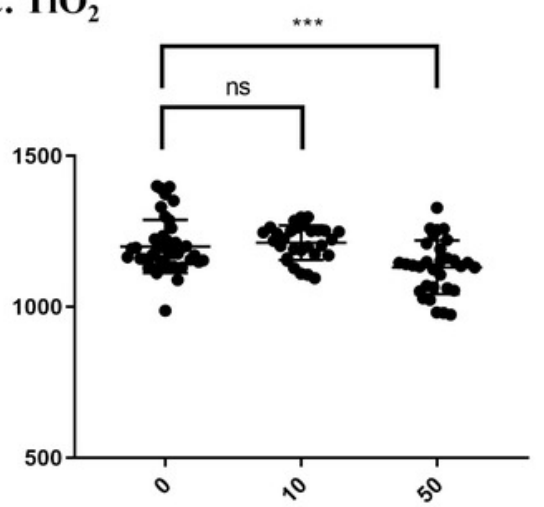

F. $\mathrm{CuO}$

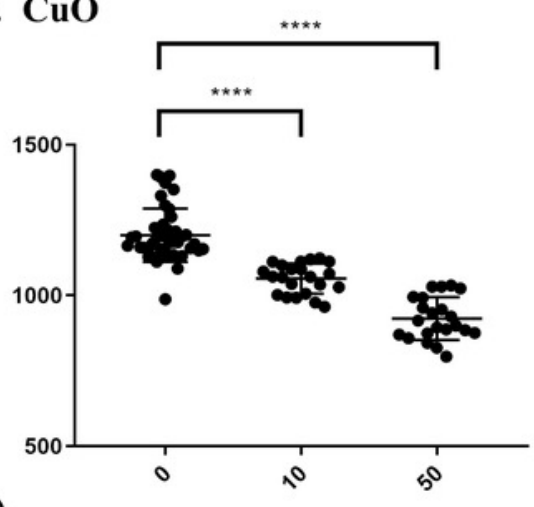




\section{Figure 3}

Reproduction capacity of $C$. elegans N2 after exposure to various nanoparticles (A. Ag, B. $\mathrm{SiO}_{2}, \mathrm{C} . \mathrm{TiO}_{2}$, D. $\mathrm{CeO}_{2}, \mathrm{E} . \mathrm{Al}_{2} \mathrm{O}_{3}$ and F. $\mathrm{CuO}$ ) at 0,10 and $50 \mu \mathrm{g} / \mathrm{ml}$.

200 L1s obtained from synchronization were seeded onto E. coli OP50-coated NGM plates and grown to the L4-young adult stage ( $48 \mathrm{~h}$ at $21^{\circ} \mathrm{C}$ ). Five L4-young adults were then transferred to a single well of a 12-well plate containing S-medium with corresponding concentrations of nanoparticles $(0,10$ and $50 \mu \mathrm{g} / \mathrm{ml})$. Plates were then incubated for $96 \mathrm{~h}$ at $21^{\circ} \mathrm{C}$. The resulting total number of progeny was then calculated by dilution. $\mathrm{Ag}, \mathrm{SiO}_{2}$ and $\mathrm{CeO}_{2}$ nanoparticles reduced the reproduction capacity in comparison with control significantly at $10 \mu \mathrm{g} / \mathrm{ml}(P<0.0001)$. Bar-graphs represent average brood size \pm standard deviation (SD) per five L4-young adult nematodes per condition.

A. Ag

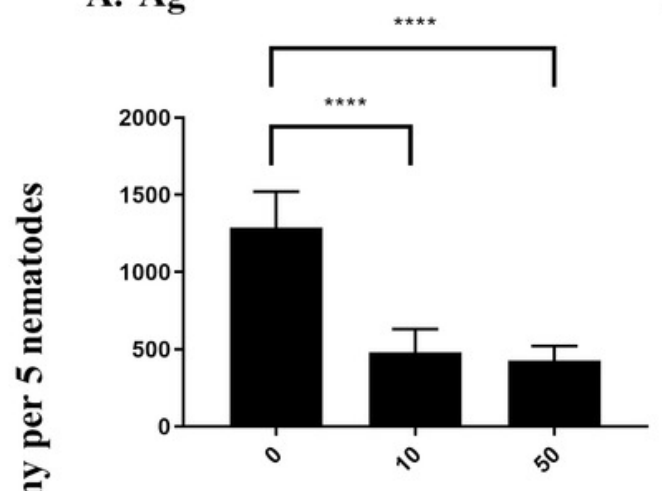

D. $\mathrm{CeO}_{2}$

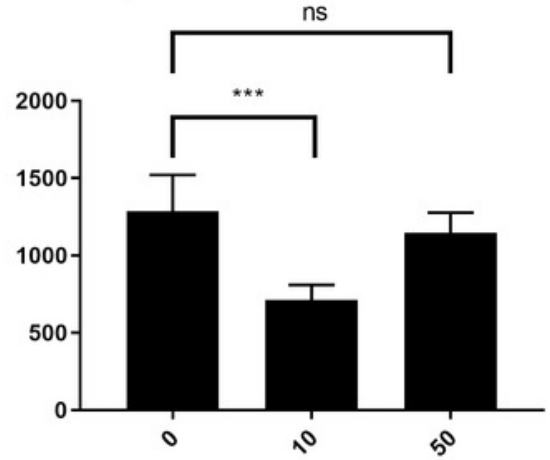

B. $\mathrm{SiO}_{2}$

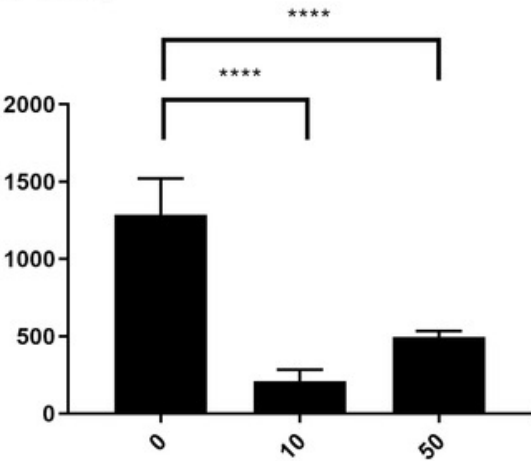

E. $\mathrm{Al}_{2} \mathrm{O}_{3}$

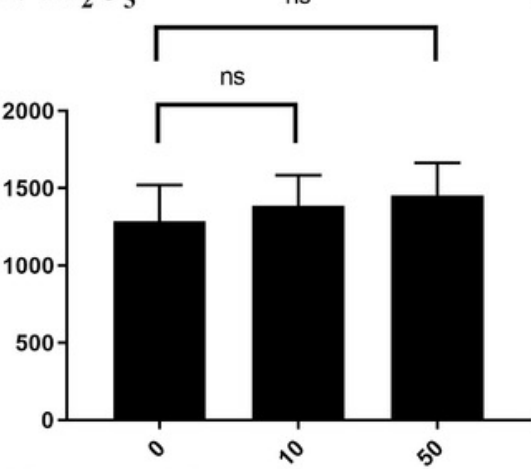

Nanoparticle concentration $(\mu \mathrm{g} / \mathrm{ml})$
C. $\mathrm{TiO}_{2}$

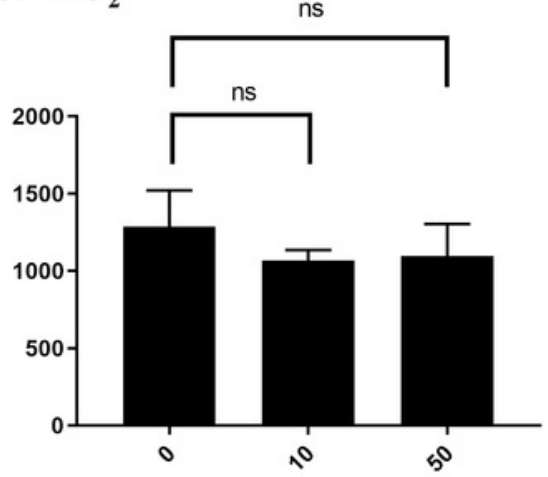

F. $\mathrm{CuO}$

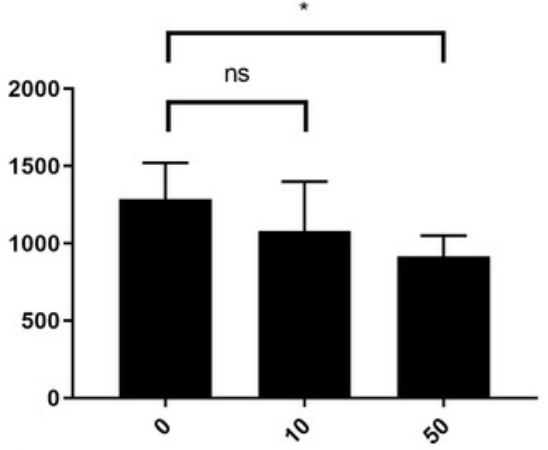




\section{Figure 4}

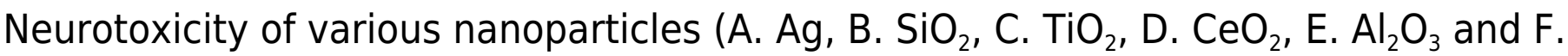
$\mathrm{CuO}$ ) to $C$. elegans $\mathrm{N} 2$ at 0,10 and $50 \mu \mathrm{g} / \mathrm{ml}$.

200 L1s were grown in 6-well plates containing S-medium supplemented with described concentrations of each nanoparticle for $72 \mathrm{~h}$ at $21^{\circ} \mathrm{C}$. Adult day 1 worms were then washed and put into an unseeded NGM plate containing K-medium and allowed to swim freely for 60

$\mathrm{s}$. The number of head thrashes made by a single worm were then counted for 1 minute. Only three nanoparticles, $\mathrm{CeO}_{2}, \mathrm{Al}_{2} \mathrm{O}_{3}$ and $\mathrm{CuO}$, show significant differences for the neurotoxicity parameter at $10 \mu \mathrm{g} / \mathrm{ml}$, compared to control $(P<0.01)$. Bar-graphs represent average number of head thrashes \pm SD per condition.

A. Ag

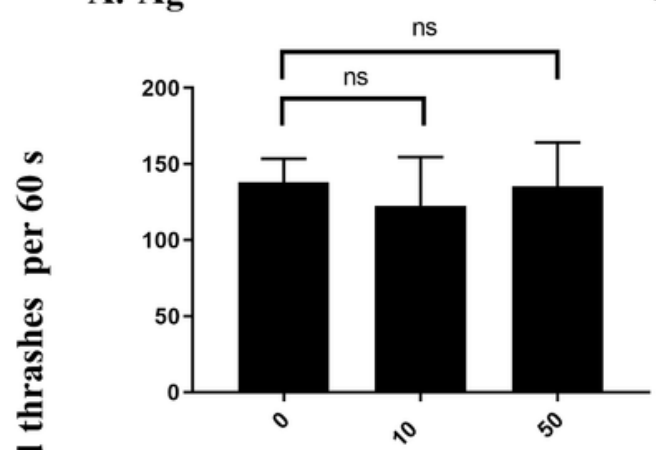

D. $\mathrm{CeO}_{2}$

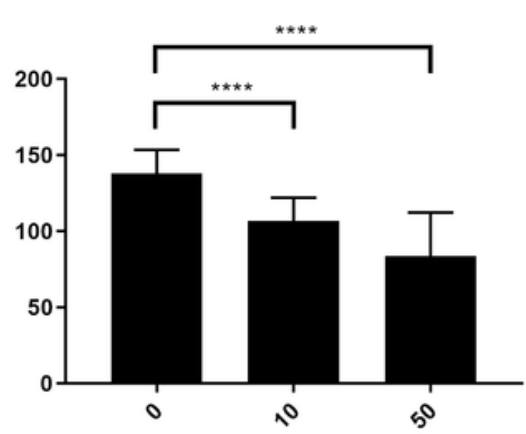

B. $\mathrm{SiO}_{2}$

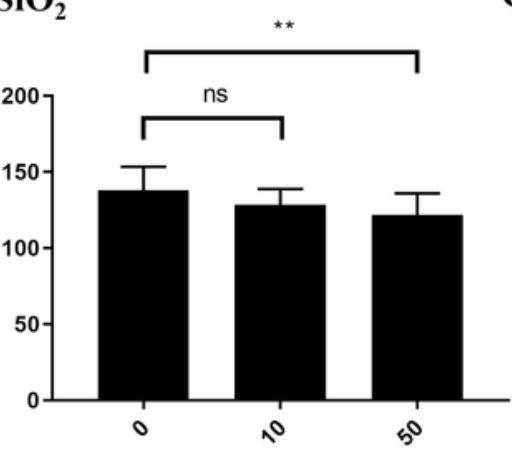

C. $\mathrm{TiO}_{2}$

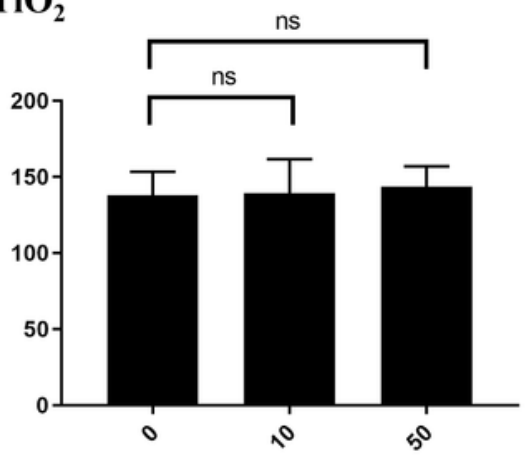

F. $\mathrm{CuO}$

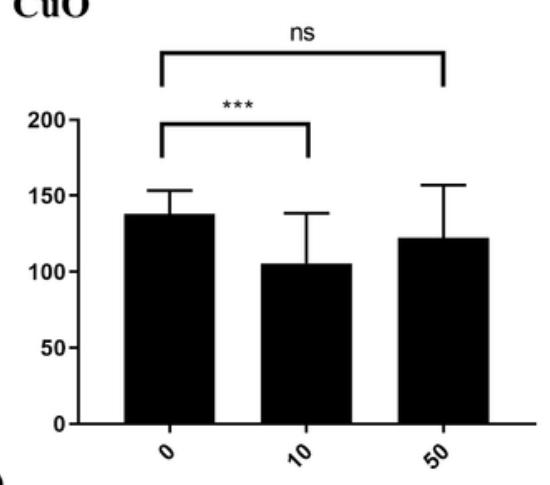




\section{Figure 5}

\section{Selected significant GO terms (detected by GSEA).}

Enriched BPs including regulation of locomotion, regulation of reproductive process and regulation of cell growth, show negative NES in the Ag group (A-C) and the SiO2 group (D-F) $($ FDR $<0.05)$.

\section{A. Regulation of locomotion}

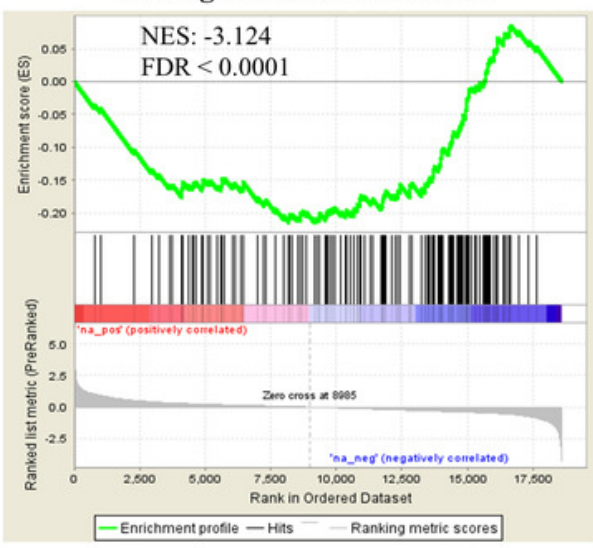

D. Regulation of locomotion

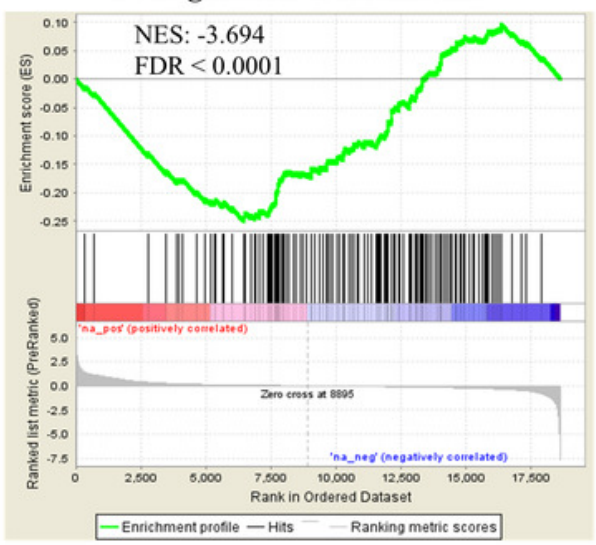

B. Regulation of reproductive process

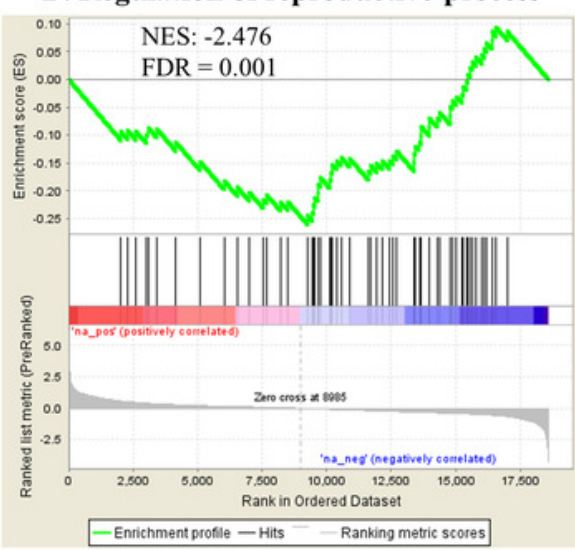

E. Regulation of reproductive process

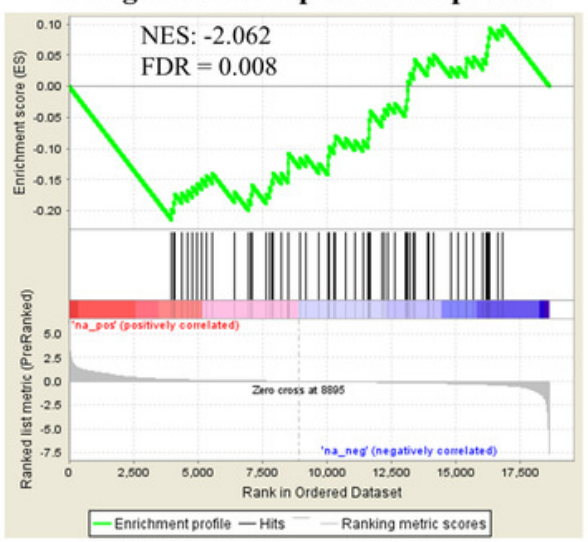

C. Regulation of cell growth

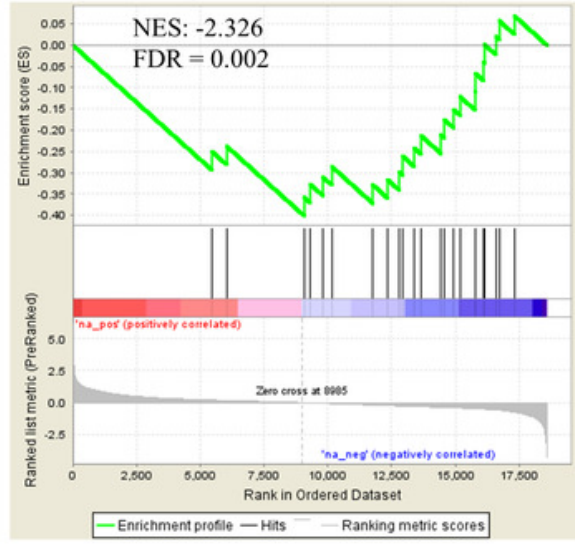

F. Regulation of cell growth

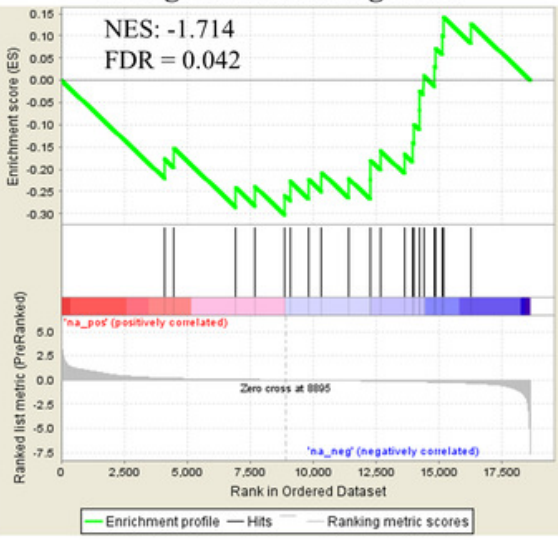




\section{Figure 6}

Heatmap of differentially expressed genes involved in the innate immune response.

A downregulation pattern is observed in the $\mathrm{SiO}_{2}$ group, in comparison with the $\mathrm{Ag}$ group and

Control (A). Pink and blue circles in Venn diagram represents differentially expressed genes

in the $\mathrm{SiO} 2$ and $\mathrm{Ag}$ groups, respectively (B). *: Ag, **: SiO2, ***: Common for Ag and $\mathrm{SiO}$. 
A.

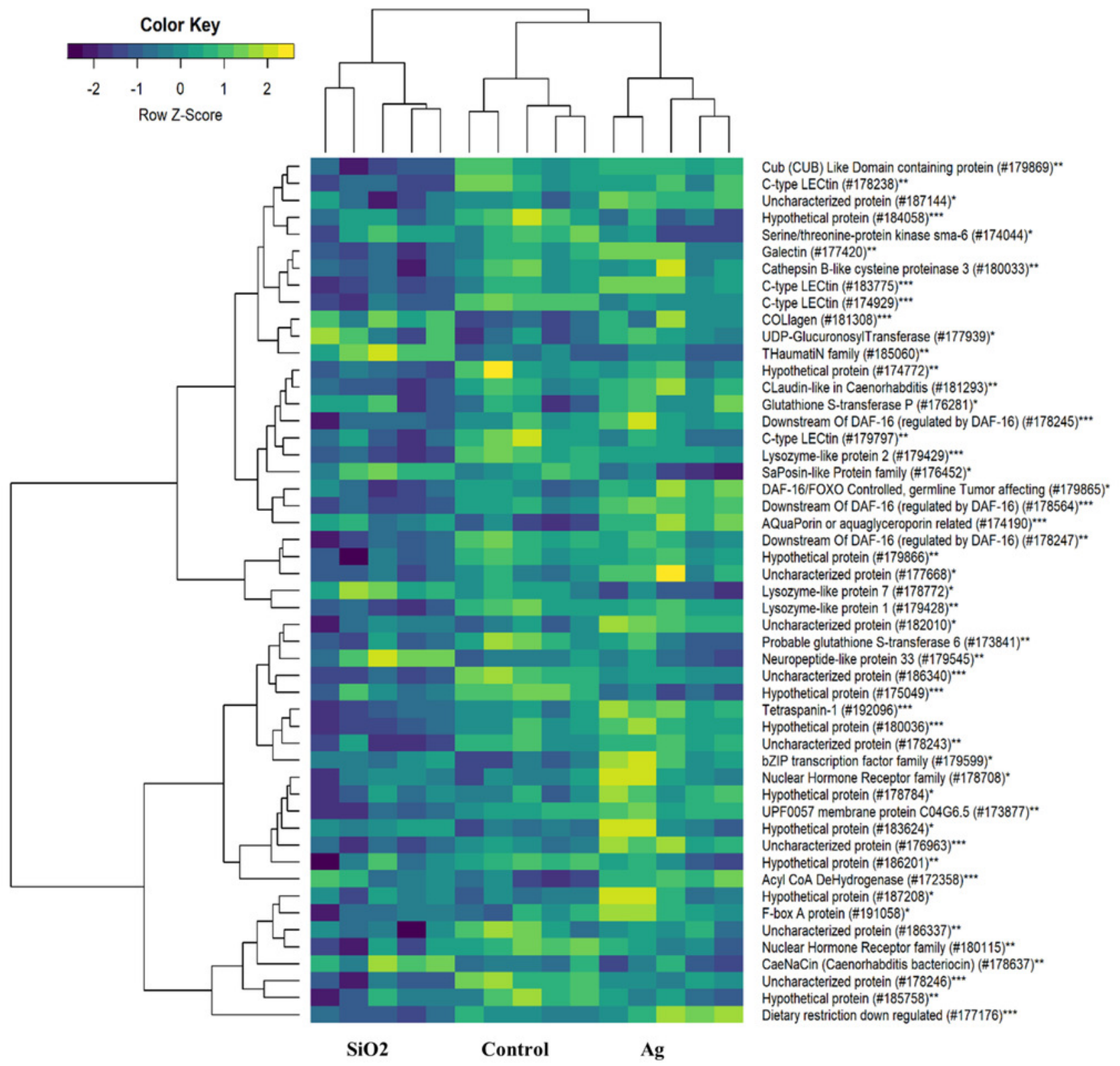

B.

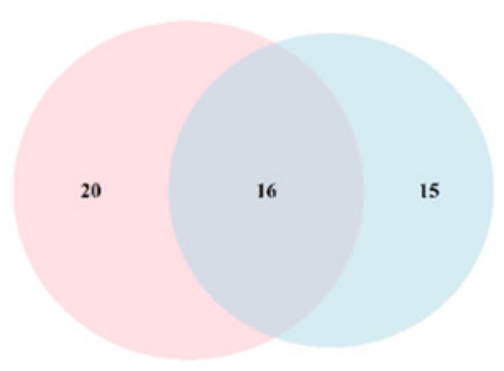


Figure 7

Selected significant KEGG pathways (detected by GSEA).

Neuroactive ligand-receptor interaction, wnt signaling pathway and MAPK signaling pathway, negatively enriched based on NES, are shown in the Ag group (A-C) and the SiO2 group (D-F) $($ FDR $<0.05)$.

A. Neuroactive ligand-receptor interaction

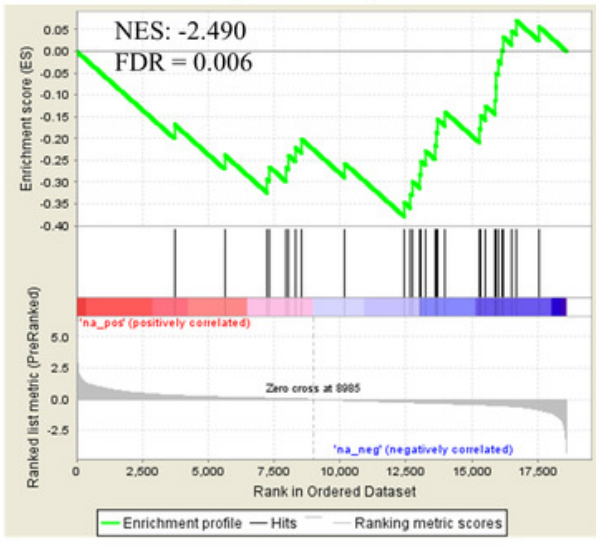

D. Neuroactive ligand-receptor interaction

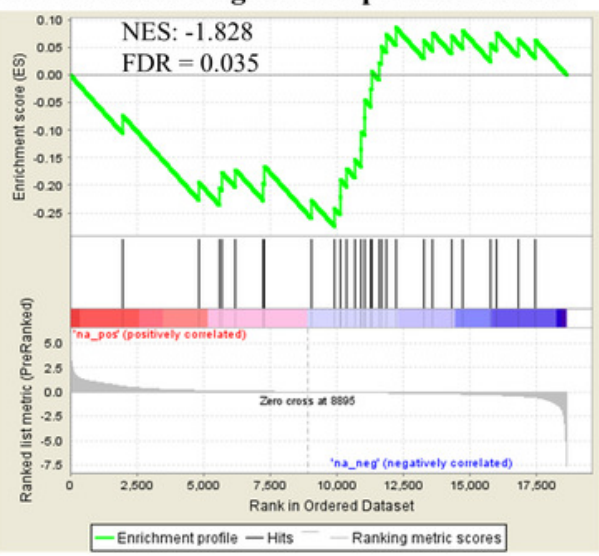

B. Wnt signaling pathway

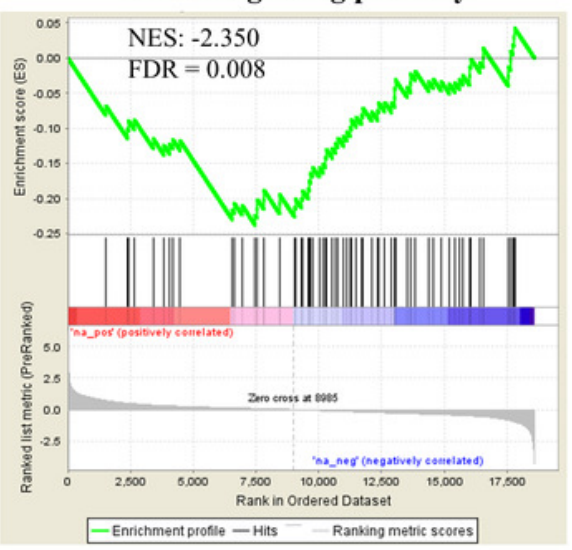

E. Wnt signaling pathway

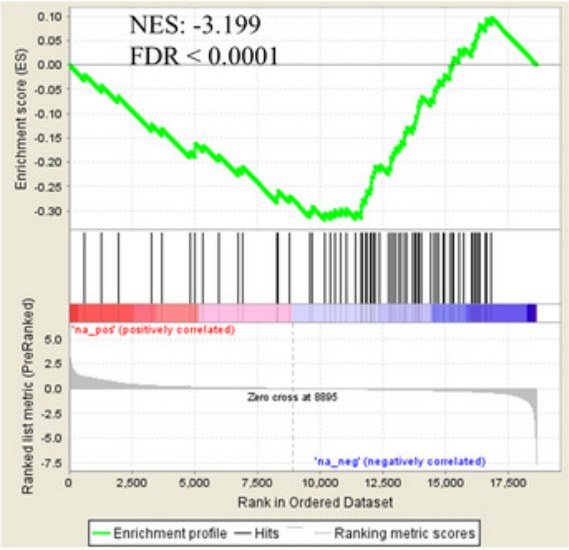

C. MAPK signaling pathway

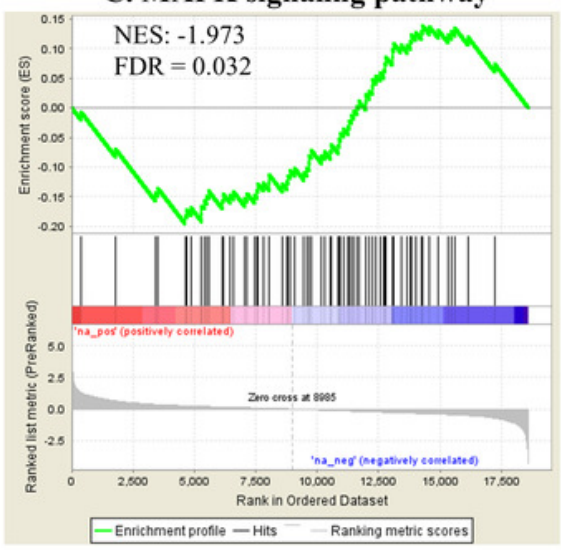

F. MAPK signaling pathway

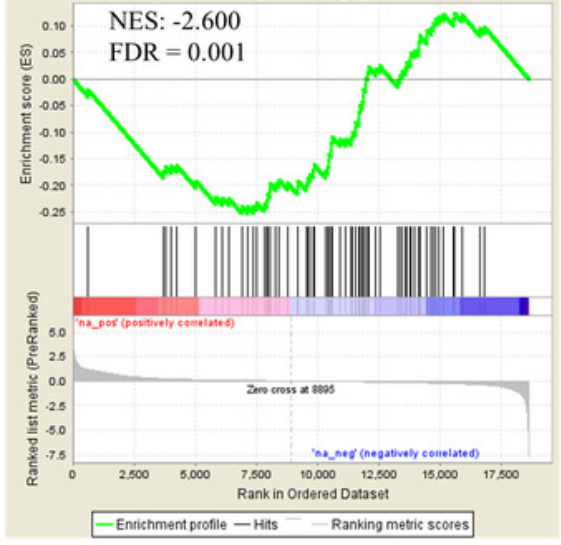


Figure 8

Proposed phenotype and transcriptome relationship in $\mathrm{Ag}$ and $\mathrm{SiO} 2$ toxicities.

The gene enrichment profiles of the biological processes and pathways are concordant with phenotype characteristics for both toxicities. Arrows indicate gene enrichment profiles with negative or positive manner.

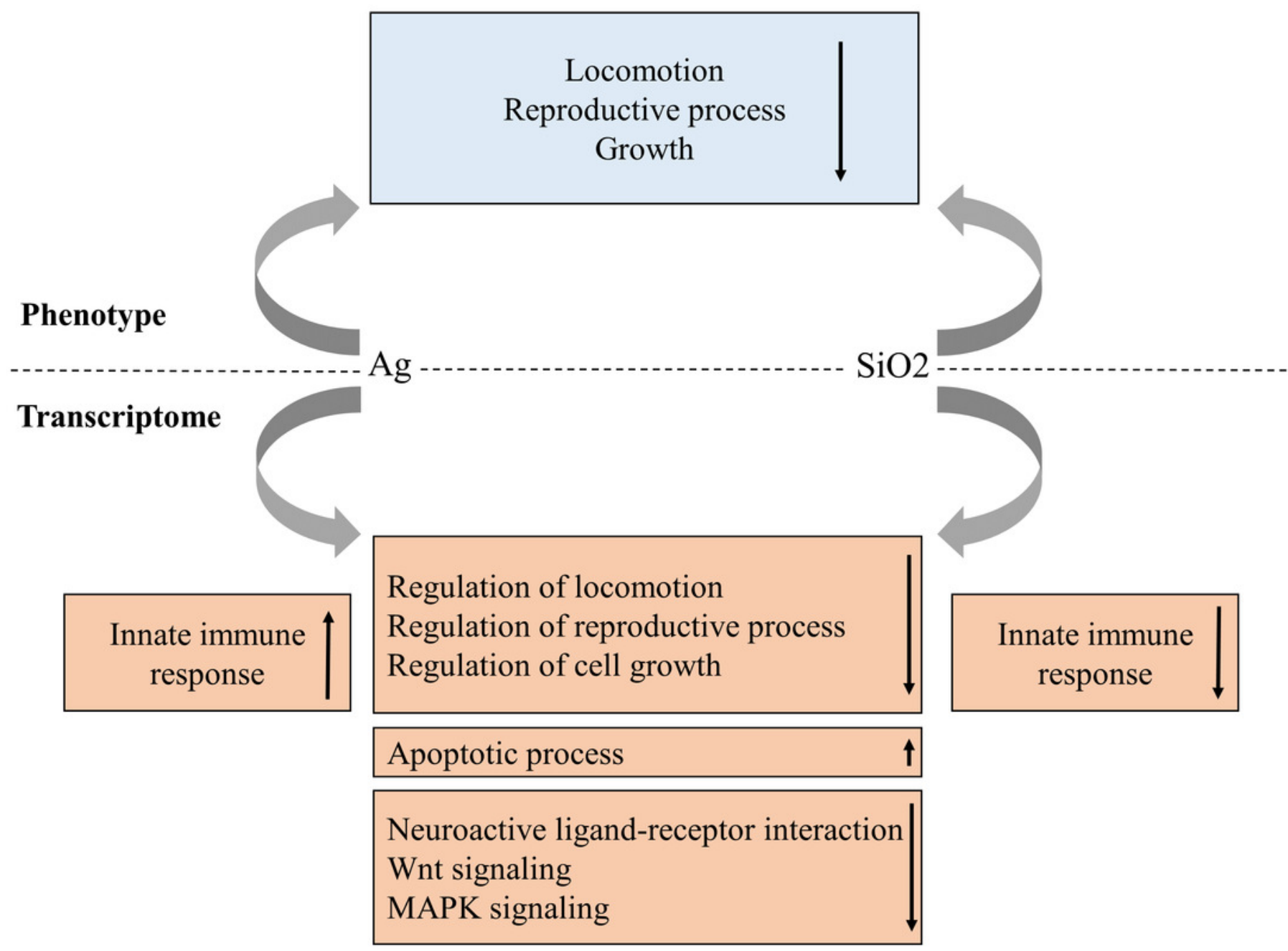

